\title{
Idioms and the syntax/semantics interface of descriptive content vs. reference
}

\begin{abstract}
The syntactic literature on idioms contains some proposals that are surprising from a compositional perspective. For example, Sportiche (2005) and Cecchetto and Donati (2015) propose that, in the case of verb-object idioms, the verb combines directly with the noun inside its DP complement, and the determiner is introduced higher up in the syntactic structure, or is late-adjoined. This seems to violate compositionality insofar as it is generally assumed that the semantic role of the determiner is to convert a noun to the appropriate semantic type to serve as the argument to the function denoted by the verb. In this paper, we establish a connection between this line of analysis and lines of work in semantics that have developed outside of the domain of idioms, particularly work on incorporation and a mixed formal and distributional semantic model developed in McNally (2017); McNally and Boleda (2017). This semantic work separates the composition of descriptive content from that of discourse referent introducing material; our proposal shows that this separation offers a particularly promising way to handle the compositional difficulties posed by idioms, including certain patterns of variation in intervening determiners and modifiers.
\end{abstract}

Keywords: idiom, incorporation, event kind, modification, reference

\section{Introduction}

Weinreich (1969:42) defined idioms as "phraseological unit[s] that involve [...] at least two polysemous constituents, and in which there is a reciprocal contextual selection of subsenses." However, at least two aspects of this selectional relation have remained challenging for linguistic theory. First, this definition, in referring to "polysemous constituents", implicitly places the focus on content words (e.g., nouns, verbs, adjectives) and sets aside function words (e.g., determiners, prepositions). Yet function words often occur within idiomatic expressions, raising questions about how selection relations between content words are managed with intervening function words. For example, consider the idiom pull strings ${ }^{1}$ in (1). The relation Weinreich described clearly holds between pull and strings, but seems able to ignore intervening material such as the determiners in (1a) and the adjectives in (1b). Much recent work on the syntax-semantics interface of idioms has focused on this problem (see below for references), but as we will show, has offered little in the way of explicit semantic analyses of the data.

to pull strings

a. to pull some/a few/those strings

b. to pull political/local strings

Second, and relatedly, idioms are famously known for manifesting varying degrees of compositionality (see, e.g., Nunberg et al. 1994; Espinal and Mateu 2010 for discussion),

\footnotetext{
* Corresponding author: Berit Gehrke, Institut für Slawistik und Hungarologie, Humboldt Universität zu Berlin, Unter den Linden 6, D-10099 Berlin, E-mail: berit.gehrke@hu-berlin.de

Louise McNally, Universitat Pompeu Fabra, E-mail: louise.mcnally@upf.edu

${ }^{1}$ Since some readers may not be familiar with some of the idiomatic expressions we use, we provide their glosses in the Appendix.
} 
ranging from fully frozen examples such as shoot the breeze, to examples like the well-known kick the bucket, whose degree of frozenness has been debated (see, e.g., Fellbaum 2015; Everaert 2017 and below), to fairly compositional cases such as those in (1), which make the selection problem visible in the first place. However, Weinreich's definition says nothing that would help us understand under which conditions idiomatic expressions might be (de)composed, and, indeed, linguists have devoted comparatively little attention to investigating whether any generalizations are possible concerning the characteristics of more vs. less compositional idioms.

In this paper we defend the view that distinguishing the semantic composition of descriptive content from composition that connects descriptive content to reference can offer new insight into such data, in a way that preserves and complements intuitions we see in previous syntactic analyses of idioms. Though the distinction between two types of compositional processes is only incipient in the formal semantics literature (see McNally and Boleda 2017; McNally 2017 for initial proposals in this direction), we see important antecedents of it in analyses of semantic (pseudo-)incorporation, especially Carlson (2003) and Farkas and de Swart (2003), but also in rich type-theoretic approaches to semantics such as those in Cooper (2005) or Asher (2011). We will adapt Farkas and de Swart's analysis to lay the groundwork for an account of determiner and adjective intervention in idioms. We want to emphasize that our goals in this paper are very specific and limited: To develop an account of idiom data that serves as an argument for a particular way of articulating semantic composition which we consider to better reflect analytical intuitions from syntactic theory, and to lay the groundwork for future, detailed accounts of the varied compositional behavior that idioms manifest. We cannot, in the space allotted to us here, exhaustively analyze the full range of idiom data.

The paper is structured as follows. In Section 2 we delimit the data, providing a brief overview of the cases in which modifiers and determiners intervene in idiomatic expressions. In Section 3 we discuss previous proposals to capture the data discussed in Section 2, pointing out their benefits and shortcomings. Section 4 spells out our account of composition in idioms and our approach to the determiner and modifier intervention effects. We will also suggest some preliminary generalizations concerning the (de)compositionality of idiomatic expressions that are possible if a distinct mechanism for the composition of descriptive content exists alongside one for the composition of referential expressions, although we must leave for another occasion developing and arguing for these generalizations in detail. Finally, Section 5 concludes.

\section{Delimiting the data}

As our main goal is to address the possibility of intervening determiners and adjectives, in this section we restrict our focus to clearly decomposable idioms ('idiomatically combining expressions' in Nunberg et al. 1994), such as our initial example to pull strings, which most readily allow for intervening material, although we extend our account to putatively nondecomposable idioms below. In the case of determiner variability more specifically, we will primarily illustrate with idioms involving verbs and direct objects, possibly accompanied by particles/prepositional phrases, as in to blow off steam (hereafter, V-N idioms). However, we 
see no reason why our analysis could not extend to other sorts of idioms. ${ }^{2}$ We begin with determiner variability, then address intervening modifiers.

\subsection{Determiner variability in idioms}

In a recent paper, Bruening et al. (2018) discuss English (as well as Korean and Vietnamese) data from the internet, in which idioms do not occur with the canonical determiners they are commonly taken to occur with. Initial inspection shows considerable variety, and the change in determiner sometimes carries along with it a change in the number of the noun involved.

Some of Bruening et al.'s examples based on idioms that canonically occur with definite determiners are given in (2). ${ }^{3}$ Here we see that the canonical (singular) definite was replaced by the (plural) indefinite some, the indefinite article, and another.
a. to rock the boat: "This'll rock some boats"
b. to bark up the wrong tree: "Have you ever barked up a wrong tree?"; "you're barking up another wrong tree"

In (3) we reproduce some of their examples in which a canonical singular indefinite article is replaced by the vague quantity expression many and the demonstrative that.

a. to smell a rat: "Do we all smell many rats connected with this legislation?"

b. to beat a dead horse: "it's moronic for a public figure to beat that dead horse of a joke"

Finally, in (4) and (5), respectively, we reproduce some of their examples of idioms that canonically appear with bare singular or bare plural nominals but that were found with definite the, indefinite some, the negative quantifier no, and, again, the vague quantity expression many, and some of them with additional adjectives as well.

a. to close up shop: "international banks have not totally closed up the credit shop"

b. to eat humble pie: "Obama might eat some humble pie"

c. to (not) make head or tail of: "He spoke so rapidly that I could make no head or tail of his speech"

a. to build castles in the air: "Mother Meade had built many castles in the air."

b. to cut corners: "This is What Happens When Companies Cut Too Many Corners and Don't Give a Damn"

c. to make tracks: "so me and Walker made some quick tracks to the truck while Ben held rear guard for us"

Determiner variability in idioms poses the following problem: How can a sub-constituent of a putatively non-compositional phrase vary? The determiner is normally assumed to form a constituent with an accompanying noun, and this in turn is assumed to form a constituent with a verb (or preposition). But determiner variability suggests that the determiner's contribution

\footnotetext{
${ }^{2}$ Note that we will not be concerned with standard "open slots" in idioms, such as the direct object in take X to the cleaners. Though such expressions are not necessarily trivial to analyze, we consider them less problematic than the sorts of cases we focus on, in which the idiomatic part of the expression itself is manipulated.

${ }^{3}$ When presenting the data, we will adopt the convention of putting the standard version of the idiom on the left, followed by a colon, and the attested examples showing variation on the right.
} 
is compositionally transparent. Thus, the noun is simultaneously in construction with a freely combining determiner, which suggests that it makes its contribution transparently, and in construction with a higher verb with which it is not related in a fully compositional way. We will address the limits on determiner variability that our analysis leads us to expect (for example, the fact that shoot the breeze practically does not have variants with alternatives to the, as far as we can determine) in Section 4.

Similar - indeed more serious - problems for the idea that idioms are non-compositional phrases are posed by intervening modifiers, to which we now turn.

\subsection{Intervening modifiers}

Modifiers intervening within idiom chunks have also been addressed by various authors (e.g., Stathi 2007; Cserép 2010; McClure 2011; Sailer 2017). In an early and very influential paper, Ernst (1981) distinguishes between what he calls external, internal, and conjunction modification. According to Ernst, we are dealing with external modification when the modifier applies to the idiom as a whole, as in (6); this kind of modification can usually be paraphrased adverbially (e.g., politically, sociologically). ${ }^{4}$

a. He made a speech in Dublin which touched a raw political nerve.

b. Don't rock the sociological boat with your new ideas.

External modification raises the problem of how to "extract" the adjective's contribution when it is encrusted in the idiom, but previous researchers have considered it less problematic than the other sorts of modification Ernst identified given that, if the semantic contribution of the adjective can be postponed until after the composition of the idiom, the pieces of the idiom itself are not compositionally separated by any intervening material.

Internal modification, according to Ernst, applies to the noun denotation alone, under its idiomatic reading, as illustrated in (7). ${ }^{5}$

a. In spite of its conservatism, many people were eager to jump on the horse-drawn ${ }^{6}$ Reagan bandwagon.

b. The federal agency decided to take the project under its well-muscled wing.

McClure (2011) argues that internal modification can only apply if the noun can be associated with idiomatic semantic content of some sort (for example, bandwagon with

\footnotetext{
${ }^{4}$ All examples in this section are from Ernst (1981).

${ }^{5}$ Nicolas (1995) attempts to reduce internal modification to external modification, in order to not have any elements intervene between idiom chunks, so that idioms can still be treated as one indivisible meaning unit. However, Chae (2015) observes that this reduction is not always possible, and indeed we do not see any way to reanalyze examples such as the following (from Ernst 1981, arguing for the same point) in terms of an adverbial modifier of the idiom based on the intervening adjective.
}

(i) a. In an extremely quixotic effort, he was casting Marxist pearls before capitalist swine.

b. In doing the project we were caught between the theoretical devil and the practical deep blue sea.

${ }^{6}$ Ernst assumes that this modifier is interpreted non-literally, describing the cause or movement (i.e., bandwagon) in a fashion that would be analogous to horse-drawn describing a physical bandwagon, i.e., as oldfashioned or conservative. 
"cause/movement" in the case of (7a)), while no such restriction applies to external or conjunction modification, an observation also implicit in Ernst (1981).

Finally, under conjunction modification, like internal modification, the modifier applies only to the noun denotation, but in this case under its literal interpretation (8).

a. In spite of the treatment the other refugees received from the rescue party in the desert, he bit his thirst-swollen tongue and kept to himself.

b. The $\$ 6,000,000$ man came over and lent us a helping electronic hand.

According to Ernst, conjunction modification adds a second proposition to the proposition associated with the idiom (in (8), he stopped himself from saying something and the $\$ 6,000,000$ man helped us, respectively); in our examples, the added propositions are he has a thirst-swollen tongue and the \$6,000,000 man has an electronic hand.

Conjunction modification is often pushed aside as word play or metalinguistic. However, any such claim requires providing a definition of word play and criteria for identifying it. Furthermore, even if we were dealing with play on words, examples like (8) show that speakers (and, presumably, hearers) can simultaneously access both the idiomatic and the literal reading of idioms (and correspondingly of idioms chunks), and we consider a semantic representation that is able to capture such a possibility more likely to be viable than one that does not.

Summarizing, this brief overview shows that we need an analysis of idioms that accounts for the idiosyncratic semantic relations between their parts, but that nevertheless allows for some flexibility in the choice of determiner and the possibility of intervening modifiers. In the following section, we present the main strategies that have been proposed for doing this.

\section{Previous accounts}

\subsection{Determiner variability as determiner independence}

We classify into three general categories the analyses of idioms that attempt to preserve a local selection relation between the content words in the idiom while allowing independence of the determiner. To keep the discussion simple, we will talk about the selection between $\mathrm{V}$ and $\mathrm{N}$, though the reader should understand that other sorts of selectional relations could be modeled similarly.

The first family of analyses adopts the strategy of representing the $\mathrm{V}$ and $\mathrm{N}$ as co-constituents, while keeping the determiner structurally separate. For example, Svenonius (2005) advocates what he calls "Banyan trees," where $\mathrm{N}$ appears in a multi-dominance structure in which it is related to both $\mathrm{V}$ and $\mathrm{D}$, but the latter are not related to each other. An example (his (35), for pull $X$ 's leg) is given in (9).

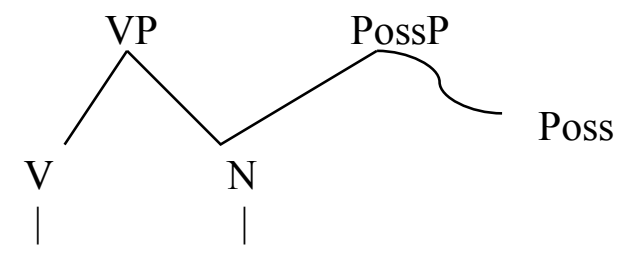


Similarly, Sportiche (2005) actually uses idiom chunks and reconstruction data to argue that determiners and nouns are "split" in underlying structure. One of his examples is given in (10), where the nominal part of the idiom, care, does not appear adjacent to the verb in its surface position, but where for semantic reasons it has to be interpreted in a lower position, leading to reconstruction of the nominal to its trace position (see, e.g., Fox 2002; Sauerland 2004; Romoli 2015 on the notion of reconstruction).

Much care seems to have been taken $t$ of the victims.

Sportiche proposes an analysis under which the verb combines with an NP in the lower position and D is generated in the higher position to which the NP moves, as in (11), where the crossed-out NP indicates the origin of movement, more precisely the copy that gets deleted at PF, i.e., not pronounced, but interpreted at LF, under reconstruction.

$$
\ldots[\mathrm{D} \mathrm{NP}] \ldots[\mathrm{NP} \mathrm{V} \ldots] \ldots
$$

A related idea is found in Cecchetto and Donati (2015), who propose that unselected elements are adjunct-like and can be late-merged; they suggest that determiners might also be latemerged, resulting in a similar syntactic separation of $\mathrm{D}$ and its accompanying nominal.

Such structures intuitively look like what we would need to account for the determiner variability illustrated in the previous section. However, the authors mentioned do not provide a semantics for them, leaving open the compositional problem of how the determiner is combined with the $\mathrm{V}+\mathrm{N}(\mathrm{P})$. It is commonly assumed that $\mathrm{D}$ elements turn property-denoting NPs (of type $<e, t>$ on extensional accounts) into DPs (of type $e$ or $<<e, t>, t>$ ) that are suitable to serve as arguments to verbs. Without the intervention of $\mathrm{D}$, the only standardly accepted technique for combining the NP and the V would be semantic incorporation (see, e.g., Van Geenhoven 1996), which effectively treats the NP as a modifier of V, thus preserving whatever type the verb has $(<e, t>$ or $\langle e,<e, t>>)$. Indeed, we will take inspiration in such an approach in Section 4, but it cannot be exploited without addressing some initial problems we point out here. First, semantic incorporation is typically morphosyntactically signaled (for example, by special case marking, or by the absence of any determiner on the incorporated nominal); there is no obvious independent evidence that it should be applied in the case of idiomatic expressions. Second, there is the problem of how to combine the D higher up: If determiners denote either functions from properties to entities or, alternatively, to generalized quantifiers, when combined with a semantically incorporated V+NP the result will not, without additional ad hoc assumptions, be the sort of thing a sentence denotes, which is what would be required (see also Bruening et al. 2018 for similar criticism).

The second family of analyses handles the locality of the selectional relation between $\mathrm{V}$ and $\mathrm{N}$ by rejecting the assumption (widely held since Abney 1987) that $\mathrm{D}$ is the head of the nominal syntactic structure and reverting to the classic analysis on which $\mathrm{N}$, rather than $\mathrm{D}$, heads the nominal phrase. Bruening (2015) and Bruening et al. (2018) are recent examples. They observe, using examples from English, Korean and Vietnamese, that local selection and facts such as those discussed in the previous section follow directly from the basic nominal structure they assume, given in (12), where "Cl" stands for "Classifier", and "Num" stands for "Numeral." 
While this analysis formally preserves the locality of selection as well as standard typetheoretic assumptions about the combination of $\mathrm{V}$ and its complement, it still leaves us with the task of providing a semantics for cases where the determiner is different from that typically associated with the idiom as well as for cases of modifier intervention.

Both of these families of syntactic analyses use the same representational vocabulary for encoding constituent structure as for managing selectional phenomena. The third family of analyses avoids this problem by separating the representation of selection from that of managing the rest of the constituent structure that drives semantic composition. Into this family falls the analysis of Bargmann and Sailer (2018), couched in the version of HeadDriven Phrase Structure Grammar (HPSG, Pollard and Sag 1994) developed in Sailer (2004). HPSG representations are feature structures that specify all of the components of linguistic signs (phonology, syntax, semantics) and the relations between them. Within the semantics, Sailer (2004) distinguishes between what he refers to as local semantics and compositional semantics. Local semantic features are where basic lexical information is stored, and are used to manage sortal and selectional restrictions between predicates and their arguments - for example, the sortal restriction of extinct to kind-level individuals as in (13a), or more pragmatic selectional restrictions of the sort in (13b) (from Sailer 2004):
a. The dodo/??Max is extinct.
b. Hans pflückte eine Pusteblume / ??ein Buch aus dem Regal.
'Hans plucked a dandelion / ??a book from the shelf.'

Compositional semantics, in contrast, regulates the combination of larger constituents, including the resolution of quantifier scope relations.

Sailer argues for keeping local and compositional semantic content separated in HPSG because sortal and selectional restrictions are insensitive to determiners and quantifiers: They hold no matter what sort of determiner/quantifier is manifest on a selected argument and, moreover, he further observes that there are no examples of predicates that select, for example, for a universal determiner no matter the lexical content of the accompanying noun. ${ }^{7}$ Once separated in the representation, the interactions between local contents can be managed via HPSG principles independently of compositional contents, avoiding the questions raised by the other families of analyses. However, like these, Sailer's model offers no explicit technique for combining the local contents in a way that would produce idiomatic meanings.

Similar in spirit, though very different in detail, is the constructional account of idioms in Chae (2015), who builds on Jackendoff (1997). ${ }^{8}$ Like Bargmann and Sailer's analysis, such an account separates the treatment of constituent structure from that of the content words.

\footnotetext{
${ }^{7}$ This point is also discussed at length in the papers by Bruening and colleagues. Although Sailer notes that one exception might be there sentences, see McNally (1992), among others, for an alternative account that does not rely on lexical selection. Note also that despite the fact that some idioms have fixed determiners, such as shoot the breeze, it is never the case that the determiner is fixed but the accompanying noun is not - that is, even in idioms with fixed determiners, selection is never for the determiner alone.

${ }^{8}$ Jackendoff does not specifically address determiner variability but only the separability of the verb from the direct object, as in The hatchet was buried.
} 
However, it posits a looser relation between these two components than does Bargmann and Sailer's analysis: the elements of the semantic representations for the idiomatic interpretations need not bear any obvious relation to the superficial components of the phrase. For example, Jackendoff proposes a simple syntax like that in (14b) for an idiom like bury the hatchet, which allows an intervening determiner (14a). This syntax is connected to the Lexical Conceptual Structure (LCS) in (14c) via the indices on the syntactic constituents (the subscripted "A" signals an open argument slot; note that this LCS does not reflect the potential for variability in the determiner, though it could be straightforwardly adapted to do so).

(14) a. Now is as good a time as any to let bygones be bygones and bury those hatchets once and for all. ${ }^{9}$

b. $\quad[\mathrm{VP} x \mathrm{~V}[\mathrm{NP} y$ Det N]]

c. $\left[\operatorname{RECONCILE}\left([]_{\mathrm{A}},[\mathrm{DISAGREEMENT}]_{y}\right)\right]_{x}$

The proposal in (14b-c) represents the idiomatic interpretation. However, in contrast to what we will see in Section 3.2, it does not overtly connect idiomatic and non-idiomatic interpretations, and this fact has opened Jackendoff's general approach to idioms to criticisms that it is stipulative and fails to capture certain aspects of idiom interpretation that do remain compositional (see, e.g., Svenonius 2005, and especially Espinal and Mateu 2010).

Summarizing, for the purposes of this paper, the similarities between these analyses of determiner variability are greater than their differences: None of them offers a particularly explicit account of the syntax-semantics interface of the idiomatic interpretation that can simultaneously account for determiner variability, the idiomatic reading, and the nonidiomatic reading. Let us now turn to analyses of modifiers intervening in idiom chunks.

\subsection{Intervening modifiers and lexical "reanalysis"}

Given the existence of modifiers applying only to the nominal element in idioms but not to the idiom as a whole, as was illustrated in Section 2.2 for internal and conjunction modification, Ernst (1981) argues for two levels of interpretation, and for the simultaneous representation of idiomatic and non-idiomatic meaning, with links between these. For example, his representation of the internal modification in (7a) is given in (15).

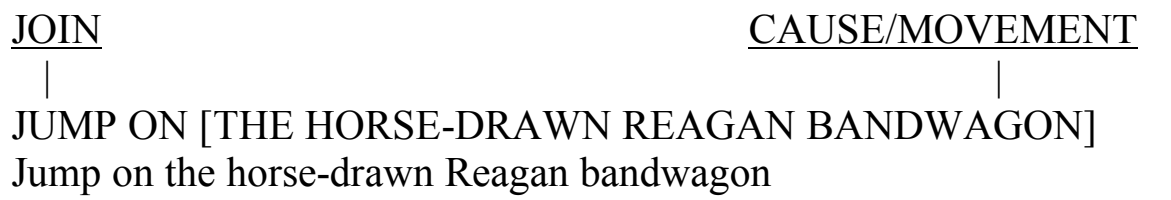

CAUSE/MOVEMENT (non-idiomatic) (surface string)

Here, the parts of the idiom, jump on and bandwagon, are linked to their idiomatic meaning (join and cause/movement), as well as to their literal, non-idiomatic meaning, and the modifier is inserted at one of these levels. Ultimately, for a complete account, one should also add something like old-fashioned/outdated at the idiomatic level, to represent the figurative meaning of the modifier as applied to the $\mathrm{N}$ under its idiomatic reading, but this is not done in Ernst's sketch of an account.

Ernst's representation of his example for conjunction modification in (8a) is given in (16).

\footnotetext{
${ }^{9}$ https://www.holidailys.com/single-post/2015/08/25/Kiss-and-Make-Up-Day.
} 


\section{CHECK SPEAKING-CAPACITY \\ $\perp$ HE HAS A THIRST-SWOLLEN TONGUE \\ BITE HIS THIRST-SWOLLEN TONGUE}

He bit his thirst-swollen tongue

Again, the parts of the idiom have literal and idiomatic meanings on distinct levels of representation: the modifier applies to the $\mathrm{N}$ on its literal, non-idiomatic meaning, and the result is a second proposition that is added as a conjunct. However, Ernst is not explicit about the precise syntactic and semantic implementation of this idea, nor does he provide a compositional account of modification in idioms; he merely points towards the starting point for such an account.

We are aware of no more detailed published analysis of internal and external modification in idioms. Nunberg et al. (1994) limit themselves to observing that such modification exists as part of a more general argument for the existence of idiomatically-combining expressions. They, Jackendoff (1997), Espinal and Mateu (2010), and Chae (2015) all express a similar intuition: That some kind of re-representation of the parts of the idioms (as in (14c)), such as coercion or metaphorical meaning extension, facilitates such modification. The question is how this intuition might be concretized. As for conjunction modification, Ernst's proposal to introduce the modifier via a second proposition strongly suggests non-restrictive modification (see, e.g., Bargmann et al. 2018). Given that non-restrictive modification has been analyzed as a Conventional Implicature (CI) (e.g., Potts 2005), delegating the semantics of such modification to a CI-like layer, as suggested by McClure (2011), would be a natural extension of Ernst's account. However, McClure offers no specific analysis of the data, and Bargmann et al. only discuss various data points that could be analyzed in terms of conjunction modification, without actually providing such an analysis. As space precludes presenting an analysis of all three kinds of modification here, we will focus on external modification below, which illustrates particular advantages of our approach and whose analysis we think could be extended to internal modification; we must set aside conjunction modification for future work.

\subsection{Summary}

We draw two conclusions from this brief review of previous work on determiner variability and modifier intervention in idioms. First, all previous syntactic accounts of determiner variability in idioms have in common a two-step syntactic derivation or two different syntactic representations. One step or representation deals with selection (e.g., of Ns by Vs) and with particular (sortal and/or other) restrictions imposed on the selected constituent, while the other takes care of the syntax of determiners, (strong) quantifiers, and classifiers. Second, previous discussions of the modification data, while still mainly informal, all point to the need for different sorts of descriptive content - both idiomatic and non-idiomatic - to be available simultaneously (and, indeed, Espinal and Mateu 2010 note that there is some evidence for this from language processing research).

These conclusions, though slightly different in nature, suggest the same, larger idea that we develop in the remainder of the paper, namely, that we need a new model of natural language meaning and its interface with syntax that 1) distinguishes the interpretive mechanisms associated with descriptive content expressions from those associated with reference-related 
expressions; ${ }^{10}$ 2) that provides a richer notion of descriptive content than mere truth conditions; and 3) that can eventually yield predictions about how these two components of meaning interact in grammar - for example, that could shed light on the fact that conjunction modification is only possible if the modified noun can be associated with a referent fitting its literal interpretation. In the following section, we present an account that works towards such a model.

\section{The analysis}

Our analysis takes initial inspiration from a potentially surprising source, namely work on noun incorporation, specifically Carlson (2003) and Farkas and de Swart (2003). ${ }^{11}$ We use two key ideas from this work: 1) Carlson's claim that incorporation involves the construction of complex event types (vs. event tokens), and 2) Farkas and de Swart's proposal to distinguish composition mediated by thematic arguments, which serve as glue between predicates and role-bearing expressions, from compositional processes that introduce discourse referents. We introduce these key ideas in Section 4.1. In Section 4.2 we bring together these ideas, building on proposals in McNally (2017) and McNally and Boleda (2017), to model descriptive content using distributional semantics; the result has the virtue of fitting well with observations in the psycholinguistics literature on the processing of idiomatic expressions. In Section 4.3 we present an analysis of idioms that brings together the insights from the previous sections and illustrate how the data from determiner variability and intervening external modification could be accounted for. For the latter data we use ideas from Gehrke and McNally (2014). In the course of our discussion, we will also advance some preliminary generalizations concerning variability in the decomposability of idioms.

\subsection{Composition of descriptive content vs. reference: Ideas from noun incorporation}

Carlson (2003) used noun incorporation to develop a particular view of how to integrate event semantics into propositional semantics. The starting point for his analysis is a crucial distinction between event types and event tokens, and the following assumption about how they are expressed in syntax:

[T] he VP is the domain of a context-free interpretive mechanism specifying an eventtype, which is then the input to the usual context-sensitive propositional semantics generally assumed for all levels of the sentence. That is, something fundamentally different goes on within the VP that does not go on 'above' the VP - it is only information about types/properties that appears there and not information about (contingent) particulars. (Carlson 2003:198)

\footnotetext{
${ }^{10}$ Note that we use the term "referential" broadly, to include aspects of meaning related to quantification, insofar as in theories incorporating a notion of discourse reference such as Discourse Representation Theory (e.g., Kamp and Reyle 1993), quantifiers, like truly referential expressions, are associated with (non-persistent) discourse referents.

${ }^{11}$ Borik and Gehrke (2015) characterize noun incorporation "in its narrow sense [as] a morphosyntactic process of incorporating a noun stem, usually unmarked for definiteness, number, and case, into a verbal stem, forming hence a compound predicate." Here, we use the term in a broader sense to include, in addition, the phenomenon of pseudo noun incorporation (Massam 2001), which shares important semantic similarities with noun incorporation, but in which the morphosyntactic relation between the relevant nominal expression and the verb is looser. See Borik and Gehrke (op cit.) for further discussion.
} 
Carlson specifically proposes that verbs denote non-functional event types and lack arguments altogether. This contrasts with the much more common assumption that verbs denote either properties of token events or relations between token events and one or more token individuals. In support of the event-type analysis, he notes that noun incorporation, which involves the combination of verbs with bare (17a) or weak indefinite $(17 \mathrm{~b})$ nominals, can be viewed as forming a structure that is of the same type as the verb and thus denotes an event subtype, as in (18) (his notation).
a. bike ride
b. collect stamps, ride a bike

\section{VP-level: $[[$ collect stamps $]] \leq[[$ collect $]]$}

Carlson leaves open how best to conceive of event types and how precisely to compose event type descriptions, but his discussion suggests that event types could be viewed as akin to the abstract entities he used to model natural kind terms in Carlson (1977). Referential and quantificational nominal expressions, whose interpretation Carlson assumes to depend on times or worlds, and thus on context, are combined with verbs not at the VP level but rather only at the IP (clause) level, in accordance with Diesing's (1992) Mapping Hypothesis. At this level, event types are mapped to event tokens. ${ }^{12}$

Building on Carlson's general idea that incorporation-like structures involve reference to event types or kinds, Schwarz (2014) provides an account of related data involving so-called weak definites. A weak definite does not (at least at first sight) involve reference to a unique entity, as regular definites are usually assumed to do. This is illustrated in (19a) (from Schwarz 2014), where a sentence with the weak definite the hospital and a universally quantified subject (every accident victim) allows for co-variation of hospitals with accident victims (see the continuation in brackets in (19a)), something which regular definites typically do not do, see (19b) (our example).

a. Every accident victim was taken to the hospital. (John to Mercy Hospital, Bill to Pennsylvania Hospital, and Sue to HUP.)

b. Every accident victim was taken to the castle. (\#John to Schloss Schwanenstein, Bill to Schloss Charlottenburg, and Sue to Schloss Plön.)

Schwarz argues that weak definites are regular definites that occur inside VPs that denote event kinds, and that in this context they get shifted to denote properties. ${ }^{13}$

While Carlson's proposal works well for incorporating structures, in which verbs combine with NPs, rather than with DPs, and presumably also for weak definites if we follow Schwarz, it is less clear how it works for non-incorporating structures with fully or strongly referential nominals. Interestingly, the proposal raises the same sorts of questions faced by syntactic accounts of idioms such as Sportiche's: How do we combine the descriptive content of DP with that of $\mathrm{V}$, ignoring $\mathrm{D}$ ? How and where do we add the information contributed by $\mathrm{D}$ ?

\footnotetext{
${ }^{12}$ See Carlson (op cit.); Gehrke and McNally (2015); Grimm and McNally (2015); Gehrke (to appear), and references cited in these works for additional discussion of the type/token distinction within the VP domain.

${ }^{13}$ For an alternative account of weak definites in terms of kinds see Aguilar Guevara and Zwarts (2011) and Aguilar Guevara (2014). At this point we are not committed to a particular account of weak definites; we merely want to point out parallels between weak definites and bare/weak indefinites, which are acknowledged on both accounts, and to build on the particular idea that VPs with such nominals involve reference to event kinds.
} 
Furthermore, we are led to ask whether one can ever form an event-type description with a referential expression in it. If one can, how is this done?

We see an answer to these questions in Farkas and de Swart's (2003) analysis of (pseudo-) incorporation, even though this analysis did not make use of a type/token distinction of the sort Carlson contemplated. Their proposal is designed to handle the contrast between incorporated bare numberless vs. plural nominals in Hungarian, illustrated in (20a) and (20b) respectively (from their p. 135, slightly adapted), in particular the fact that the latter but not the former introduce discourse referents that can be picked up by anaphora. In this respect bare plurals behave like non-incorporated DPs with determiners, as shown in (20c), even though in other respects they behave like incorporated, property-denoting expressions.

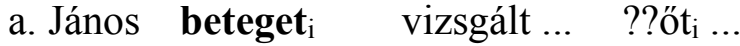
Janos patient-ACC examine.PAST him
'Janos patient $\mathrm{i}_{\mathrm{-}}$-xamined ... ??him $\mathrm{i}$...'
b. János betegeket bizsgált ... $_{i} \quad$ őket $_{i} \ldots$
Janos patient-PL.ACC examine.PAST him

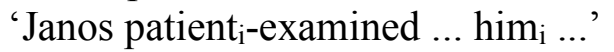
c. János egy beteget t $_{\mathrm{i}} \quad$ vizsgált ... öt $_{\mathrm{i}} \ldots$
Janos a patient-ACC examine.PAST him
'Janos examined a patient $t_{i} .$. him $_{i} \ldots$ '.'

The analysis is implemented in Discourse Representation Theory (DRT, Kamp and Reyle 1993), in which semantic interpretation is read off a logical representation that is in turn generated from the syntax via a set of construction rules. All DRT representations, called Discourse Representation Structures (DRSs), crucially separate discourse referents from the conditions that these referents must satisfy. However, in the version of DRT that Farkas and de Swart use, which draws on a proposal in Koenig and Mauner (1999), a second crucial distinction is made: the variables corresponding to discourse referents (and which instantiate the arguments of a predicate), are distinguished from the variables for so-called Thematic Arguments, which serve the double function of compositional glue and of representing the arguments that need to be saturated. These features are illustrated in the DRSs in (21), which represent the contribution of the indefinite DP in (20c) ${ }^{14}$ where $x$ is a thematic variable and $u_{x}$ is a discourse referent.
a. beteget: $<\{\},\{$ patient $(x)\}>$
b. egy beteget: $<\left\{u_{x}\right\},\left\{\operatorname{patient}\left(u_{x}\right)\right\}>$

Simplifying considerably, a DRS is embeddable (i.e., truthfully evaluable) in a model if there is some assignment of values to discourse referents such that all of the conditions on those referents are satisfied.

To get from (21a) to (21b), and to manage semantic composition involving thematic arguments and discourse referents more generally, Farkas and de Swart propose two different kinds of semantic composition rules. First, they propose Unification of thematic arguments, shown in (22), which allows two descriptive contents to be composed via identification of some thematic argument in each of them, as shown for the composition of (21a) and (23a) in

\footnotetext{
${ }^{14}$ Instead of using the more familiar DRT "box" notation, we represent DRSs here as tuples, where the left-most element of the tuple is a set of discourse referents, and the second, the conditions these referents must satisfy. A third element will be added to the tuple as we proceed.
} 
$(23 b)$.

(22) Unification of thematic arguments: Replace the relevant thematic argument $z$ of a verbal predicate with the thematic argument $x$ contributed by a nominal argument of the verb. (Farkas and de Swart 2003: 65, variable names changed for expository purposes)

a. vizsgált: $<\{\},\{\operatorname{examine}(e, y, z)\}>$

b. beteget viszgált: $<\{\},\{$ patient $(x)$, examine $(e, y, x)\}>$

A DRS containing a thematic argument can be evaluated as true in a model if there is an embedding for the DRS in that model on which some entity satisfies all of the conditions associated with the thematic argument. In other words, thematic arguments behave rather like narrow scope existentially quantified variables in predicate logic, but they lack the properties specifically associated with discourse referents (e.g., potential to license discourse anaphora).

Second, to associate thematic arguments with discourse referents, Farkas and de Swart propose a small family of instantiation rules. A(rgument)-Instantiation, shown in (24), substitutes a variable corresponding to a discourse referent in the place of the variable corresponding to a thematic argument in the discourse representation of a predicate, effectively saturating it.

(24) A(rgument)-Instantiation: Instantiate the $n$-th thematic argument of a verbal predicate by the discourse referent contributed by the fully interpreted nominal argument. (Farkas and de Swart 2003: 33)

Given the Hungarian facts in (20), Farkas and de Swart propose that there are two distinct means by which a nominal can be "fully interpreted", that is, associated with a discourse referent. The standard means is by what they call D(eterminer)-Instantiation: A determiner can contribute a discourse referent for the thematic argument of its nominal complement, as stated in (25).

(25) $\mathbf{D}$ (eterminer)-Instantiation: Instantiate the thematic argument $z$ of the NP by the discourse referent $u$ contributed by material under $\mathrm{D}$, and subscript $u$ with the index $x$, writing $u_{x}{ }^{15}$ (Farkas and de Swart 2003: 35)

As their system is designed, D-Instantiation for a given nominal obviously precedes AInstantiation of a thematic argument by that nominal; combining (21b) and (23a) yields (26). ${ }^{16}$

$$
\text { egy beteget viszgált: }<\left\{u_{x}\right\},\left\{\text { patient }\left(u_{x}\right), \text { examine }\left(e, y, u_{x}\right)\right\}>
$$

However, for bare plurals, where there is no determiner, Farkas and de Swart posit a different mechanism for instantiating the nominal's thematic argument, which they call Secondary Instantiation (see (27)). They propose that the presence of plurality indicates that the speaker effectively presupposes a plural discourse referent $\left(a_{x}\right.$ in $\left.(27)\right)$ - if this were not the case, there would be no reason for the speaker to use the plural. The hearer must accommodate this

\footnotetext{
${ }^{15}$ The subscripts are introduced by Farkas and de Swart for bookkeeping purposes. We follow their convention here.

${ }^{16}$ The association of the nominal referent with the appropriate verbal thematic argument is managed by the DRT syntax/semantics interface - the so-called DRS construction rules -, which we do not show here.
} 
presupposition, and in so doing the thematic argument of the bare plural, as well as any thematic arguments it has unified with, are effectively instantiated. ${ }^{17}$

(27) Secondary Instantiation: Instantiate the thematic argument $x$ of a nominal with a discourse referent $a_{x}$ that it is co-indexed with. (Farkas and de Swart 2003: 49)

Slightly adapting their notation, we represent presupposed discourse referents as elements of a third set in the DRS:

\section{betegetet: $<\{\},\{$ patient $(x)\},\left\{u_{x}\right\}>$}

(28) can combine with a verb via Unification of thematic arguments, exactly parallel to (23); the verb's argument can subsequently be saturated by Secondary Instantiation. Crucially, Farkas and de Swart make the following comment:

Secondary Instantiation, unlike D-Instantiation, is driven by the presuppositional semantics of the plural rather than by the lexical input of the syntactic configuration. Unlike D-Instantiation, Secondary Instantiation is not triggered by a [specific syntactic configuration], and therefore its application is not tied to a particular point in the derivation [italics ours $-\mathrm{BG} / \mathrm{LMcN}$ ]. It is a last resort strategy that allows a discourse referent contributed by the plural feature to connect to the thematic argument of the nominal in the absence of a proper binder. (Farkas and de Swart 2003: 48-49)

That is, Farkas and de Swart provide a mechanism for dissociating the linking of (thematic) arguments from the instantiation of discourse referents. Though they do not avail themselves of this option in the case of DPs, we see no strong reason not to do so. After all, DPs quite generally convey number, and the same sort of speaker presupposition that supports Secondary Instantiation for bare plurals should justify Secondary Instantiation for any DP's discourse referent. We also have not identified any immediately undesirable effects of eliminating D-Instantiation altogether in favor of Secondary Instantiation, although this is a topic that merits further study (see also footnote 23 for an additional related comment).

Both Carlson and Farkas and de Swart thus establish the groundwork for distinguishing the composition of descriptive content-contributing expressions from that of composing potentially complex descriptive contents with reference-related expressions. Farkas and de Swart provide the mechanics: Though Secondary Instantiation might be criticized (as DRT often is on other grounds) for appearing non-compositional, we note that they have grounded this rule in a form of presupposition accommodation - in effect, they take seriously and exploit the pragmatics of reference and effectively offer a radically different view of the way in which number contributes to the construction of meaning. This view of meaning construction differs in important ways from views of meaning that more closely build on the Montagovian tradition, but insofar as we find similar intuitions expressed in unrelated syntactic literature (as evident in Section 2.1), and insofar as Farkas and de Swart's account

\footnotetext{
${ }^{17}$ Farkas and de Swart do this to distinguish bare plurals from bare numberless nominals, which lack the ability to license discourse anaphora. We refer the reader to their work for detailed discussion of the data.

Note also that it is arguably more appropriate to consider this contribution of the plural as some other sort of non-asserted content (or "projective meaning") than a presupposition, insofar as the hearer is not required to be familiar in advance with the discourse referent in question: After all, the referent introduced by a bare plural is novel in the discourse, in contrast to the referent presupposed by, for example, definite DPs. We will use the term "speaker presupposition" to refer to this contribution here, but must leave investigation of exactly what type of meaning this is for future research.
} 
can shed light on data that is out of reach of classical formal semantic analyses, we think it should be considered seriously.

Carlson, in contrast, provides a different sort of insight. His appeal to (effectively hyperintensional) types suggests that the key to a better analysis of descriptive content involves modeling it as something closer to a concept description, as opposed to in a classically referential fashion. In the next section, we introduce a technique for doing exactly this, which has, as a plus, the benefit of providing promising representations for the complexities of idiomatically combining expressions.

\subsection{Enriching descriptive content and descriptive content composition}

In a paper that includes both original research and a review of psycholinguistic work on idiomatic expressions, Titone and Connine (1999) argue that idioms are processed simultaneously in a compositional and non-compositional ("long word") fashion. The results in this literature and Titone and Connine's own work echo results in the literature on the processing of literal vs. figurative (i.e., metaphorical or metonymic) meanings, which suggests that when a word or phrase is processed, initially all of its interpretations are activated, with irrelevant meanings only later suppressed (see, e.g., Swinney 1979; Rubio Fernández 2006; Hogeweg, to appear; and references cited there). From this work one can draw the conclusion that representations for both idiomatic phrases and words should reflect this connectedness. Symbolic representations of the sort typically used in linguistic theory do not do this very successfully. In contrast, distributional semantic models provide a convenient way to model just the characteristics this psycholinguistic research suggests that we need.

In the simplest versions of distributional semantics, semantic values for words and phrases are represented as vectors, i.e., arrays of numerical values that reflect statistical co-occurrence in a corpus. There are many ways to construct such representations, but by way of example, for each word of interest (e.g., kick), we could collect occurrences of that word, within a sentence-sized window, with each of the 10000 most frequent nouns, verbs, adjectives and adverbs in the corpus. Each component in the vector will reflect the count of the word of interest with one of these 10000 words. Table 1 presents an artificially constructed example of a portion of what the vectors might look like for the verbs kick and pull. ${ }^{18}$

Table 1 Sample vectors for kick and pull

\begin{tabular}{|l|l|l|l|l|l|l|l|l|l|}
\hline & $\ldots$ & child & politician & bucket & strings & hard & slowly & run & $\ldots$ \\
\hline kick & $\ldots$ & 99 & 55 & 100 & 0 & 100 & 1 & 78 & $\ldots$ \\
\hline pull & $\ldots$ & 105 & 170 & 0 & 200 & 80 & 50 & 0 & $\ldots$ \\
\hline
\end{tabular}

\footnotetext{
${ }^{18}$ Two technical comments: First, the extracted vectors are almost always eventually normalized (to avoid distortions due to the fact that words vary independently in frequency irrespective of their co-occurrences with the word of interest) and compressed to facilitate processing, typically to 300-400 dimensions. Second, in the last several years, it has become common to use deep learning techniques to train systems to be able to predict a choice of word given a context, or to predict a context given a word. The lexical representations that result from these techniques, though similar in important ways to the models described in this paper, do not reflect statistical corpus distributions of words in the way that classic distributional models do, and are thus referred to as "distributed" or "word embedding" models (see Mikolov et al. 2013 for an early and influential example of the latter and Baroni et al. 2014 for comparison of the two approaches to modeling), rather than as "distributional". For the purposes of this paper, the differences between the sorts of models are not crucial.
} 
As Table 1 shows, the vectors for different words will vary in real numerical values across the components that correspond to a latent feature, rather than varying in the presence or absence (or value) of discrete features or entailments. For example, the relative punctuality of kicking events will be indirectly encoded in low or nonexistent co-occurrences with adverbs like slowly.

Though distributional semantic models lack the transparency of symbolic representations, they have various features that make them useful for analyzing descriptive content. ${ }^{19}$ First, their non-discrete nature renders distributional representations particularly useful for the analysis of linguistic phenomena where similarity or analogy plays a role, and where hard category distinctions are difficult to draw. Second, because distributional representations are based on statistical corpus co-occurrences with a wide variety of words, these models do not distinguish properly "linguistic" meaning from world knowledge or conceptual content. Third, for essentially the same reason, the representations are, in a sense, "overspecified" as opposed to "underspecified," and typically not disambiguated; disambiguation is effectively achieved only in context.

These characteristics, especially the second, may initially raise concerns for semanticists interested in truth conditions, but they all illuminate observations in the literature on idioms. Idioms are a form of figurative language use, and such language has been argued to involve either similarity-based reasoning (see, e.g., Bowdle and Gentner 2005) or ad hoc feature assignment (e.g., Glucksberg 2001). Such processes depend crucially in many cases on much more than limited truth conditional information. For example, the idiom to pull strings is claimed to have its origins in analogy to the control of marionettes by puppeteers, information unavailable in the truth conditions associated with the component words or (literal) phrase. Moreover, the "overspecified" representations fit well with psycholinguistic evidence about the early activation of word meanings mentioned above.

Despite these differences with what is found in symbolic, and especially formally-oriented, semantic models, distributional representations share one crucial characteristic with the latter: They can be composed through algebraic operations that can take into account syntactic information, particularly grammatical function or thematic role information. ${ }^{20}$ Composition effectively contributes to disambiguating vectors by strengthening components that are shared by the composed expressions and weakening (though not necessarily eliminating) those that are not shared. We return to this point in the next subsection.

Interestingly, representations for phrases can also be extracted directly in exactly the same way as are those for words. This opens up additional possibilities in the analysis of idioms.

\footnotetext{
${ }^{19}$ Indeed, they have a long history in information retrieval and in psychology (where they were developed for Latent Semantic Analysis, Landauer and Dumais 1997), although we cannot address here the complex question of the relation between distributional representations and models of concepts. Our immediate motivation for adopting them is the fact that they have properties that we consider interesting for modeling descriptive content and that they can be relatively easily constructed and tested. Distributional representations also currently dominate computational semantic approaches to lexical representation. Lenci (2018) provides an accessible introduction with historical context and technical details; we refer the reader to his work, and limit ourselves here to focusing on the general features that are immediately relevant.

${ }^{20}$ See Pham (2016) for discussion of the varied ways syntax can be exploited in compositional distributional semantics. It is interesting to note that in one of Pham's studies compositional distributional semantic models largely ignored constituent structure information involving function words, even when that information was fed into the system, suggesting that such models might combine especially well with syntactic frameworks that treat grammatical function and constituent structure separately, such as Lexical Functional Grammar or any number of models that have been applied in natural language processing since at least Klein and Manning (2002).
} 
For example, the extracted vector for an idiomatic expression (e.g., pull strings or kick the bucket) can be compared with the vectors of the component content words. These and other measures allow one to estimate the degree of compositionality of an idiomatic expression: Senaldi et al. (2016) show that a higher degree of idiomaticity correlates with greater semantic distance between the vector for an idiom and the vectors of its component parts. The results of distributional modeling have been shown to correlate with speaker judgments concerning idiomaticity as well (Lebani et al. 2016). Finally, the fact that both directly extracted and composed idiom representations are possible fits well with the psycholinguistic observations in Titone and Conine (1999): Representations for full idiomatic expressions could be stored in addition to representations for their components; in processing, either or both might be accessed. Finally, Liu et al. (2017) provide a specific illustration of how idiomatically interpreted expressions can be composed from distributed representations for non-idiomatic components; the option of composing an idiomatic expression from component parts offers the prospect of modeling not only some of the variants on idioms discussed in this paper but also variants such as pull wires for pull strings.

Despite their usefulness for the analysis of (type- or concept-like) descriptive content, distributional semantic models are currently not well suited to modeling the semantics of function words or token reference. Though attempts are ongoing to provide distributional semantic models for full fragments of language (see, e.g., Hedges and Sadrzadeh 2016 and other ongoing work by Sadrzadeh and colleagues), other approaches have opted for using them to model only lexical meaning (e.g., Garrette et al. 2011; Lewis and Steedman 2013; see also the papers in Boleda and Herbelot 2016 for related discussion). We adopt this second strategy in the following section and show how it can account for the data from Section 2.

\subsection{The analysis of idioms}

We integrate distributional semantics into the Farkas and de Swart (2003) version of DRT by substituting compositional distributional semantics for their treatment of descriptive content, inspired in the strategy used by McNally and Boleda (2017) for connecting descriptive contents to discourse referents. In this latter work, compositional distributional representations play a role analogous to types or kinds, which are instantiated by (or, intuitively, serve to categorize) discourse referents. The recasting of types as distributional representations is motivated on various grounds in McNally (2017) and fulfills our goal of bringing Carlson's (2003) insights together with Farkas and de Swart's.

Nouns will introduce descriptive contents modeled as vector representations, which we represent in small caps (e.g., STRING for string); we refer to the descriptive content of an expression $\alpha$ as $d(\alpha)$; see (29a). We set aside the possibility of modification for the moment and assume that the descriptive content of a noun is inherited by the NP immediately containing it (29b). Similarly, the descriptive content of a DP will be identical to that of the NP that it immediately dominates $(29 \mathrm{c}) .^{21}$
a. $d(\mathrm{~N}): \mathbf{N}$
b. $d(\mathrm{NP})=d(\mathrm{~N})$
c. $d([\mathrm{DP} \mathrm{D} \mathrm{NP}])=d(\mathrm{NP})$

\footnotetext{
${ }^{21}$ We assume a very simple syntax here, but our proposal can be adapted to a more sophisticated syntax.
} 
Our treatment of verbs follows Paperno et al. (2014), which is one of several recent proposals to bring a notion akin to function application into distributional semantics. On their analysis verbs are represented as $n$-tuples consisting of a vector plus one matrix for each of the verb's arguments. ${ }^{22}$ Thus, for pull, the representation will be a triple, which we annotate as $<$ PULL $^{v}$, PULL $^{\text {su }}, \mathbf{P U L L}^{\mathbf{o b}}>$, where superscript $v$ indicates a vector, su indicates a matrix that will apply to the subject nominal's vector, and ob indicates a matrix that will apply to the object nominal's vector. The composition technique involves multiplying $(\otimes)$ the last matrix in the tuple associated with a verb with the vector contributed by the corresponding argument, adding $(+)$ the result to the verb vector, and carrying along any remaining matrices:

$$
\begin{aligned}
& \text { a. If } d(\mathrm{~V})=<\mathbf{V}^{v}, \mathbf{V}^{\mathbf{s u}}, \mathbf{V}^{\mathbf{o b}}>\text {, and } d(\mathrm{DP})=\mathbf{N} \text {, then } d([\mathrm{vP} \mathrm{V} \text { DP }])=<\mathbf{V}^{v}+\mathbf{V}^{\mathbf{o b}} \otimes \mathbf{N}, \mathbf{V}^{\mathbf{s u}}> \\
& \text { b. If } d\left(\mathrm{VP}_{1}\right)=<\mathbf{V}^{v}, \mathbf{V}^{\mathbf{s u}}>\text {, and } d(\mathrm{DP})=\mathbf{N} \text {, then } d\left(\left[\mathrm{VP} 2 \mathrm{DP} \mathrm{VP}_{1}\right]\right)=\mathbf{V}^{v}+\mathbf{V}^{\mathbf{s u}} \otimes \mathbf{N}
\end{aligned}
$$

In addition to computational advantages, this technique offers a means of composing a verb's descriptive content with those of its arguments in a compositional fashion; see Paperno et al. (2014), Pham (2016) for discussion. For simplicity, in the rest of this paper we use the shorter $d(\alpha)$ notation for all descriptive contents.

The composition process in (30) fulfills the role that Unification of thematic arguments fulfills in Farkas and de Swart's analysis. It allows us to do without this rule and, indeed, without thematic arguments altogether. However, we now need to hook up the descriptive contents to discourse referents. Consider first the nominal domain. We follow Farkas and de Swart in assuming that number morphology adds the speaker presupposition of an atomic or non-atomic discourse referent. In addition, we add the condition that this referent realizes the description contributed by the noun's vector ( $\mathbf{R}$ is inspired in Carlson's 1977 realization relation, as discussed in McNally 2017); Secondary Instantiation can be reduced to copying the speaker-presupposed referent to the set of instantiated referents in the common ground. ${ }^{23}$ Determiners contribute nothing to the descriptive content, though they may add independent conditions on discourse referents, for example related to their novelty or quantity. (31) illustrates (using two as a sample determiner).

$$
\begin{aligned}
& \text { a. }[\mathrm{NP} z \mathrm{~N}]:<\{\},\left\{\mathbf{R}\left(u_{z}, d(\mathrm{NP})\right)\right\},\left\{u_{z}\right\}> \\
& \text { b. }\left[\mathrm{DP} \text { two } \mathrm{NP}_{z}\right]:<\{\},\left\{\mathbf{R}\left(u_{z}, d(\mathrm{DP})\right),\left|u_{z}\right| \geq 2\right\},\left\{u_{z}\right\}>
\end{aligned}
$$

The treatment of verb phrases will be similar. We take verbs to speaker-presuppose an event referent that realizes the verb's descriptive content. The descriptive content for phrases containing the verb will be computed as in (30) above. Any relations between speakerpresupposed referents and descriptive contents will be inherited, as in (32), where $V_{t}$ is a transitive (2-argument) verb:

$$
\text { a. }\left[\mathrm{V}_{\mathrm{t}}\right]:<\{\},\left\{\mathbf{R}\left(u_{e}, d\left(\mathrm{~V}_{\mathrm{t}}\right)\right)\right\},\left\{u_{e}\right\}>
$$

\footnotetext{
${ }^{22}$ A matrix is a 2-dimensional vector. Intuitively, the matrix for a given verb (e.g., pull) has the effect of relating the vectors for words to the vectors for the phrase consisting of the verb plus those words (e.g., it will relate the vector for strings to that for pull strings, that for candy to that for pull candy, etc.). We should note that, although we find various features of Paperno et al.'s approach attractive, the architecture we propose could be adapted to other implementations of compositional distributional semantics.

${ }^{23}$ Though a more conservative alternative would eschew the speaker-presupposed discourse referents and eliminate the Secondary Instantiation step in favor of placing referents directly in the referents list, Henriëtte de Swart (p.c.) has suggested that an approach like the one we adopt in the text could be developed into a technique for modeling different scopal possibilities, in addition to fitting better with their general account of incorporated bare plurals. The question of how best to manage discourse referents must be left for future research.
} 
b. [vP1 $\left.\mathrm{V}_{\mathrm{t}} \mathrm{DP}_{z}\right]:<\{\},\left\{\mathbf{R}\left(u_{e}, d\left(\mathrm{VP}_{1}\right)\right), \mathbf{R}\left(u_{z}, d\left(\mathrm{DP}_{z}\right)\right)\right\},\left\{u_{e}, u_{z}\right\}>$

c. $\left[\mathrm{VP} 2 \mathrm{DP}_{y}\left[\mathrm{VP} 1 \mathrm{~V}_{\mathrm{t}} \mathrm{DP}_{z}\right]\right]$ : $<\{\},\left\{\mathbf{R}\left(u_{e}, d\left(\mathrm{VP}_{2}\right)\right), \mathbf{R}\left(z, d\left(\mathrm{DP}_{z}\right)\right), \mathbf{R}\left(y, d\left(\mathrm{DP}_{y}\right)\right)\right\},\left\{u_{e}, u_{z}, u_{y}\right\}>$

The resulting relation between the conditions is somewhat loose in two respects. First, the discourse referents for events and their participants are related to each other not directly, but only indirectly via the fact that the descriptive content of the VP is modulated by the descriptive contents of its arguments, and the latter are connected to discourse referents for the event's participants. Second, the descriptive content of any DP, though modulated in composition with that of the verb to which it serves as an argument, stands in relation to its discourse referent in unmodulated form. We tighten these aspects up by introducing thematic relations between the referent for the event described by the verb and those of each of its participants, as in (33). For purposes of illustration, we assume that direct object participants are themes (Theme) and subject participants are agents (Agent), though of course any appropriate thematic roles could be introduced.

$$
\begin{array}{r}
\text { a. }\left[\mathrm{vP} 1 \mathrm{~V}_{\mathrm{t}} \mathrm{DP}_{z}\right]:<\{\},\left\{\mathbf{R}\left(u_{e}, d\left(\mathrm{VP}_{1}\right)\right), \mathbf{R}\left(u_{z}, d\left(\mathrm{DP}_{z}\right)\right), \text { Theme }\left(u_{z}, u_{e}\right)\right\},\left\{u_{e}, u_{z}\right\}> \\
\text { b. }\left[\mathrm{vP}^{\prime} 2 \mathrm{DP}_{y}\left[\mathrm{vP} 1 \mathrm{~V}_{\mathrm{t}} \mathrm{DP}_{z}\right]\right]:<\{\},\left\{\mathbf{R}\left(u_{e}, d\left(\mathrm{VP}_{2}\right)\right), \mathbf{R}\left(z, d\left(\mathrm{DP}_{z}\right)\right), \mathbf{R}\left(y, d\left(\mathrm{DP}_{y}\right)\right),\right. \\
\text { Theme } \left.\left(u_{z}, u_{e}\right), \operatorname{Agent}\left(u_{y}, u_{e}\right)\right\},\left\{u_{e}, u_{z}, u_{y}\right\}>
\end{array}
$$

Secondary Instantiation can subsequently apply to instantiate the speaker-presupposed discourse referents.

Note that in relating the discourse referents explicitly, we also tighten up the connection between the descriptive contents. Recall that distributional representations are not, in principle, disambiguated in the absence of context: Intuitively, if one hears string out of context, one does not know whether this refers to a fiber that can be used to tie up a package, a part of a violin, a list of numbers, or some kind of influence, among other possibilities. Thus, if a referent stands in relation to the representation for a noun, this will not, in and of itself, tell us in virtue of exactly which properties it stands in that relation. ${ }^{24}$ However, the conditions that come from the descriptive content of the VP contribute to this disambiguation, just as if we hear pull strings, we can rule out that the referent associated with strings is a list of numbers, for example. Nonetheless, the full content associated with the noun remains present in the representation, if weakened. We hypothesize that this feature could be exploited to account for the accessibility of the literal meaning of nouns under conjunctive modification in idiomatic expressions.

We can now contrast the representation of an idiomatically combining expression like pull strings with that for an in principle non-compositional expression like kick the bucket. The former results straightforwardly from (29)-(33), as shown in (34).

$$
\begin{aligned}
& \text { a. }[\mathrm{vt} \text { pull] }]:<\{\},\left\{\mathbf{R}\left(u_{e}, d(\text { pull })\right)\right\},\left\{u_{e}\right\}> \\
& \text { b. }\left[\mathrm{NP} z \text { strings] }:<\{\},\left\{\mathbf{R}\left(u_{z}, d(\text { strings })\right)\right\},\left\{u_{z}\right\}>\right. \\
& \text { c. [vP pull strings]: }<\{\},\left\{\mathbf{R}\left(u_{e}, d([\mathrm{vP} \text { pull strings }])\right), \mathbf{R}\left(u_{z}, d(\text { strings })\right), \text { Theme }\left(u_{z}, u_{e}\right)\right\}, \\
& \qquad\left\{u_{e}, u_{z}\right\}>
\end{aligned}
$$

For kick the bucket, the simplest option is to associate the full string directly with a vector

\footnotetext{
${ }^{24}$ For those concerned with truth conditions, one should think of the truth conditions associated with the realization relation between a referent and distributionally modeled descriptive content (e.g., $\mathbf{R}\left(u_{z}, d\left(\mathrm{DP}_{z}\right)\right)$ ) as underdetermined, rather than as conflicting.
} 
extracted for the entire phrase along with a matrix for composing with the subject, as in (35a). Since the descriptive content for the phrase is not compositionally generated, there will be no referent introduced for the object noun phrase, and thus the resulting DRS will have only a presupposed referent for the event described by the VP.
a. $d$ (kick-the-bucket): < KICK-THE-BUCKET ${ }^{v}$, KICK-THE-BUCKET ${ }^{\text {Su }}>$
b. [vp kick the bucket]: $<\{\},\left\{\mathbf{R}\left(u_{e}, d(\right.\right.$ kick-the-bucket $\left.\left.)\right)\right\},\left\{u_{e}\right\}>$

However, there are other options. We could adapt Farkas and de Swart's treatment of bare numberless nouns (recall (23)), which they argue introduce no referent at all (not even via speaker presupposition), and analyze the bucket as contributing only descriptive content (36).
a. $[\mathrm{vt} k i c k]:<\{\},\left\{\mathbf{R}\left(u_{e}, d(k i c k)\right)\right\},\left\{u_{e}\right\}>$
b. [DP the bucket]: $<\{\},\{d($ bucket $)\},\{\}>$
c. [vp kick the bucket] $:<\{\},\left\{\mathbf{R}\left(u_{e}, d([\mathrm{vP}\right.\right.$ kick the bucket $\left.\left.])\right)\right\},\left\{u_{e}\right\}>$

This would perhaps constitute one way to flesh out a treatment of the bucket as a weak definite, though it leaves open the question of how to handle the contribution of the definite article (but see the discussion in Section 4.1, and Aguilar Guevara and Zwarts 2011, Aguilar Guevara 2014, and Schwarz 2014 for particular proposals). ${ }^{25}$ Since weak definites are not our focus, however, we will not pursue this possibility here.

Finally, the idiom could be treated analogously to pull strings in (34), modulo the contribution of the definite article, and minimally differently from (36) in including a speaker-presupposed referent for bucket, as (37):

$$
\begin{aligned}
& \text { a. [vt kick]: }<\{\},\left\{\mathbf{R}\left(u_{e}, d(\text { kick })\right)\right\},\left\{u_{e}\right\}> \\
& \text { b. [DPz the bucket] }:<\{\},\left\{\mathbf{R}\left(u_{z}, d(\text { bucket })\right),\left|u_{z}\right|=1\right\},\left\{u_{z}\right\}> \\
& \text { c. [vp kick the bucket] }:<\{\},\left\{\begin{array}{r}
\mathbf{R}\left(u_{e}, d([\mathrm{vP} \text { kick the bucket }])\right), \\
\left.\left.\qquad \mathbf{R}\left(u_{z}, d(\text { bucket })\right),\left|u_{z}\right|=1, \text { Theme }\left(u_{z}, u_{e}\right)\right\}\right\},\left\{u_{e}, u_{z}\right\}>
\end{array}\right.
\end{aligned}
$$

As with pull strings, this representation does not by itself distinguish literal bucket kicking from the idiomatic sense related to dying, and it differs crucially from the representations in (35) and (36) insofar as it requires a second participant that instantiates the descriptive content contributed by bucket and fulfills the Theme role in the event described by the VP.

This analysis of idiomatic expressions, especially the non-compositional ones, might initially look too weak at best, and problematic at worst. However, when combined with an appropriate theory of language use, and so contextualized, we think it has some important advantages.

A hearer who knows how to interpret kick, the, and bucket will have two choices when hearing kick the bucket (used with idiomatic intent) for the first time. She might infer from the context that the phrase refers to a dying event and simply associate the phrase directly with that reference, as in (35). She might also perceive that the phrase has parts that she

\footnotetext{
${ }^{25}$ One indication that it is, indeed, a weak definite, is that a sentence with a universally quantified NP in subject position gives rise to covariation of (whatever metaphorical) buckets with elements of the subject domain, just as was found with the weak definite in (19a); see (i).
}

(i) Every accident victim kicked the bucket. 
recognizes, and attempt to associate those parts with participants in the dying event - in other words, she might try to reconstruct a compositional interpretation by decomposing the description. In this case, her knowledge of the definite article will tell her to associate bucket with a unique individual. At this point, inference will take over and several options are possible - Glucksberg (2001) offers illustrative examples in an extensive discussion of kick the bucket. Such inferences will play a role in our discussion in the next subsection, although it is beyond the scope of this article to spell out their workings in detail. Note also that the distributional approach to representing descriptive contents fits well with the hypothesis that these contents are dynamically updated via exposure to use.

Though each of these alternatives raises some questions that require further study, we hope to have shown that separating the composition of descriptive content from the association of that content with referents introduces a certain flexibility that could be exploited in idiomatic expressions. We now return to determiner variability.

\subsubsection{Factors involved in determiner variability}

To make sense of determiner variability in idioms we first ask how the event type described on the idiomatic reading is related to the interpretation on the non-idiomatic reading. In all cases, we will assume that some form of analogical reasoning or ad hoc categorization decision supports the association of the idiomatic descriptive content with whatever is described.

One significant form of analogy involves event structure, as evident in observations by e.g., Glasbey $(2003,2007)$ and subsequent work (e.g., Espinal and Mateu 2010). We thus expect that the determiner may vary depending on the relation between the participant described by the direct object (whether literally or idiomatically) and the event structure of the whole VP. For idioms with canonical definite objects, insofar as the definite determiner reflects the uniqueness of the object participant in the event, replacing it with an indefinite either induces iterativity/plurality or genericity on the event. For idioms with canonical indefinite objects, determiner variability generally changes the measure/plurality properties of the event. In these cases, change to a definite determiner is less likely, unless it is required by an adjective like same or usual, or unless the event participant is discourse old.

We illustrate these observations starting with the idioms with canonical definite objects in (38).

(38) a. to kick the bucket

b. to bend X's ear

We assume that these are idioms based on the structures of the literally described event types (a semelfactive for kick the bucket; an activity for bend X's ear) that involve contextually unique direct object participants, and that, crucially, such events can be counted by counting those participants. If the definite article reflects this uniqueness, determiner variation should be possible if it makes sense contextually for there to be more than one such event in question. Precisely such variation is illustrated in (39). ${ }^{26}$

\footnotetext{
${ }^{26}$ Bruening et al. (2018) report that they did not find variation with the idiom kick the bucket. This is unsurprising insofar as the idiom describes a dying event, which is usually unique per participant. Everaert's example in (39a) clearly works because it describes various people dying.
} 
(39) a. Far more people pass on, push up daisies, kick buckets, visit Davy Jones' locker, or journey to the great beyond, than simply die. (Everaert 2017)

b. to bend a few receptive ears ${ }^{27}$

Similarly, idioms with canonical indefinite or bare objects as in (40), which signal the quantity of the literally or idiomatically described individual participating in the event, allow variation of the sort in (40b), for example.
a. to blow off steam
b. to blow off a lot of steam

As with the examples in (38), the idiomatic use of such phrases is based on the structure of the event type in question, but for idioms with indefinites there is no uniqueness implication and therefore we do not find the definite article among the typical alternatives. Rather, the measure of the object referent serves to measure the size of the result of the literally or idiomatically described event (unspecified in (40a), large in (40b)), or some other measure of the described event, as seen in several examples below.

Let us now return to Bruening et al.'s (2018) idioms with canonical singular definite nominals from (2), repeated in (41).

a. to rock the boat: "This'll rock some boats"

b. to bark up the wrong tree: "Have you ever barked up a wrong tree?"; "you're barking up another wrong tree"

In (41), the definite determiner signals the contextual uniqueness of the direct object participant with respect to the described event; thus, a change in determiner indicates reference to (potentially) more than one such event. (41a), where the noun also appears in plural, talks about an unspecified number of instances of rocking the boat - that is, of equilibrium-disturbing events. In the first example in (41b), an indefinite is in the scope of the temporal quantifier ever, indicating co-variation of events with times. In the second example in (41b), we are dealing with a second (another) instantiation of an event of barking up the wrong tree.

In (42) we repeat from (3) Bruening et al's (2018) examples with determiner variability in idioms involving canonical indefinites.

a. to smell a rat: "Do we all smell many rats connected with this legislation?"

b. to beat a dead horse: "it's moronic for a public figure to beat that dead horse of a joke"

The measure of the object referent in (42a) serves to measure the number of events: It is suspected that more than one (unknown) thing went wrong - each object referent correlates

There has been considerable controversy over the origin of the idiom kick the bucket and thus over the type of event upon which the idiom was based; however, it is important to note that it does not matter what the original bucket participant actually was or what role it played, as long as current users of the idiom construe it as a unique participant that crucially co-varies with the event. Indeed, it is even possible for the bucket to be construed as the resulting death. See Liberman (2016) for discussion of the controversial origins of this idiom.

${ }^{27} \mathrm{http}: / /$ www.bbc.co.uk/blogs/adamcurtis/2011/03/goodies_and_baddies.html. 
with one event. We expect that with the right discourse, i.e., if it is already known what went wrong, it should also be possible to use this idiom with a definite determiner, and indeed such examples are attested:

[In a forum discussing a scam] Great that you smelled the rat. ${ }^{28}$

Similarly, in (42b), the demonstrative that instead of the indefinite article allows reference to an individual previously introduced into the discourse or otherwise familiar.

Finally, consider Bruening et al.'s examples of determiner variability in idioms with canonical bare count/mass and plural nominals in (4) and (5), repeated in (44) and (45).

(44) a. to close up shop: "international banks have not totally closed up the credit shop"

b. to eat humble pie: "Obama might eat some humble pie"

c. to make head or tail of: "He spoke so rapidly that I could make no head or tail of his speech"

(45) a. to build castles in the air: "Mother Meade had built many castles in the air."

b. to cut corners: "This is What Happens When Companies Cut Too Many Corners and Don't Give a Damn".

c. to make tracks: "so me and Walker made some quick tracks to the truck while Ben held rear guard for us"

The bare noun in the literal interpretation of the idiom in (44a) is used to refer to an institution; bare nouns are highly restricted in the kinds of modification they allow, and when they are modified, a determiner often needs to be added, turning the bare noun into a weak definite (see, e.g., Aguilar Guevara 2014 on the complementary distribution of bare nouns and weak definites). The determiner some in (44b) and (45c) is used proportionally to measure the size of the events, insofar as there is an incremental relation between the amount of what is eaten and the number of tracks made and the progress of the respective events. $N o N$ in $(44 \mathrm{c})$ and many in $(45 \mathrm{a}, \mathrm{b})$ behave similarly: No is used as an alternative to the canonical not... [any] $N$, where head or tail is associated with a mass participant corresponding to the sense or understanding that is (not) achieved; many indicates a contextually high number of events of the type described by the idioms in question. We also found an example for the idiom in (45b) in which some signals a contextually low number of events:

Every company occasionally has reason to cut some corners. ${ }^{29}$

Thus, mapping of some participant from the literal to the idiomatic interpretation is certainly an important part of idiomatic language use, even if those participants are not always transparently identifiable in the common idiomatic paraphrase (as is the case with kick the bucket).

We now turn to examples where the determiner is not variable, or extremely limited in variability. These fall into at least three types. First, there are cases, such as those in (47), where the analogy underlying the idiom appears to be unrelated to event structure.

a. to shoot the breeze $\approx$ to converse idly

\footnotetext{
${ }^{28} \mathrm{https}: / /$ www.paypal-community.com/t5/Fraud-phishing-and-spoof-Archive/Scam/td-p/68280/page/4.

${ }^{29} \mathrm{https}: / /$ dev.to/isaacandsuch/comment/105o.
} 
b. to chew the fat $\approx$ to make friendly familiar conversation

These phrases describe pointless activities on their literal interpretation, and this pointlessness is the analogical basis for the idiom. However, the pointlessness has nothing to do with the event structure per se, that is, with the number or type of participants and their roles. On the literal interpretation, the definite determiner signals contextual uniqueness: there is only one ambient breeze, and the fat is uniquely part of whatever piece of meat it belongs to. To the extent that these participants do not have counterparts in the event described by the idiom, we find no determiner variation. ${ }^{30}$

Second, there are cases where something similar happens with just the idiomatically interpreted nominal. This is arguably the case of the indefinite nominal in to have a ball, for which Bruening et al. (2018) found no determiner variation. Here, a ball, which refers literally to a dance, according to the Oxford English Dictionary, is analogically connected to the associated effect or state that the dance produces, namely fun (cf. the light verb construction to have fun). The fact that fun has mass reference but ball does not arguably limits the options for determiner variation, although we would expect that the definite determiner, which is compatible with both, might appear as an alternative, and indeed the constructed example in (48) sounds acceptable to us.

\section{Remember the ball/fun we had at the party?}

In this case, the definite article serves as a discourse cataphor for the event description in the relative clause.

Finally, in some cases identified by Bruening et al. (2018), there is no determiner variation for reasons that are independent of idiomaticity as such. One such example is to hit home. It is independently known that home (and its equivalent in other languages) is unique, for example, being the only bare noun allowed in constructions that in (Standard) English require a preposition (and sometimes also a determiner) with other nominals, e.g., go home vs. go *(to the) supermarket (see, e.g., Jackendoff 1993; Collins 2007; Terzi 2010). In those cases where home refers to the home of an indexically identified individual, it is not common to add a determiner (or a preposition or adjective, for that matter): \#I go to my home. We therefore do not expect to find one in this idiom, which describes a situation whose implicit experiencer is the individual indexically associated with home.

We showed above in (35)-(37) how interpretations for idiomatic expressions could be represented both in a direct and in a composed fashion. Examples like those in (47), which are not decomposable, will be represented analogously to (35); the decomposable idioms will be represented as in (36) or (37). Note that in separating the composition of the descriptive content from that involving expressions that link that content to referents - here, the determiners - we fully expect that determiners in the decomposable cases should be able to vary, and the differences that arise in interpretation due specifically to the different effects of the determiners should be explainable in exactly the same way as they have been explained already in the literature on non-idiomatic expressions.

\footnotetext{
${ }^{30}$ Bruening et al. (2018) note that they found shoot some breeze in their corpus search. Our account would force us to posit a reconstructed association between the direct object and what is said in an idle conversation, effectively treating some breeze like a cognate object.
} 
In sum, we expect that determiner variability in idioms depends on the way in which the event type described on the idiomatic reading is related to the event type described on interpretation on the non-idiomatic reading. Crucially, however, we do not expect that everything goes, a point which is not addressed in Bruening et al. (2018). Note, for example, the contrast in (49), which is reinforced by the fact that internet searches rendered several hits for (49a) but none for smell all rats.
a. to smell every rat
b. (??)to smell all rats

In quantifying distributively over the nominal referent, each instance of which is associated with a single event, the determiner every in (49a) effectively quantifies over events of smelling a rat (in the idiomatic sense), whereas the quantifier all in (49b) on its most salient interpretation forms a maximal plurality of referents that loses the correspondence to the individual atomic events that are described by this idiom. This contrast also emerged for other idioms that we searched of this type: all appeared far less often than did every, which was attested in examples like those in (50).

(50) a. We're raised not to rock the boats that men are clearly the captains of. But fuck that. I'll rock every boat. I can swim. ${ }^{31}$

b. We don't have to beat every dead horse to a pulp. ${ }^{32}$

The effect of counting or measuring an event indirectly by counting/measuring a unique participant in it is also found with certain sorts of adjectival modifiers, such as so-called adverbially-used frequency adjectives like frequent. We will extend the strategy of leveraging the modification of a distinguished participant in order to indirectly attribute a property to an event - which was deployed for frequency adjectives in Gehrke and McNally (2014) - to external modification in idioms. As will become clear, this strategy will effectively reduce external modification to a special case of internal modification. We therefore focus exclusively on external modification in the next section to present our approach to the phenomenon of intervening modifiers.

\subsubsection{Towards an account of intervening modifiers: The case of external modification}

Reviewing Ernst's (1981) examples of external modification, we note that external modifiers are either relational adjectives (RAs) (51), or noun modifiers (52).

(51) a. Carter doesn't have an economic leg to stand on.

b. We need to blow off a little theoretical steam here.

c. To the old men in the Kremlin, beset with problems, the world is far from a Soviet oyster.

(52) a. He denied that the Saudis, angry over Death of a Princess, were seeking some celluloid revenge with a movie of their own.

b. Our team is not as good as last year's, but we aren't going to drop out of the soccer picture.

c. He broke new inkwell ground with his invention.

\footnotetext{
${ }^{31} \mathrm{https}: / /$ twitter.com/thecherness/status/984492308795199488.

${ }^{32} \mathrm{http}$ ://www.readingeagle.com/news/article/letter-socialism-threatens-american-way-of-life.
} 
We conjecture that both types of modifiers involve a contextually specified relation $R$ between modifier and modifiee, as commonly assumed in accounts of RAs. Building on McNally and Boleda (2004) and Arsenijević et al. (2014), we start with the logical representation for RAs shown for political in (53).

$$
\text { political: } \lambda P_{k} \lambda x_{k}\left[P_{k}\left(x_{k}\right) \wedge R\left(x_{k}, \text { politics }\right)\right]
$$

Under this semantics, political expresses a contextually specified relation $R$ between the modified nominal referent (represented as a kind, $x_{k}$ ) and politics. We take RAs to be sortally unrestricted, so they can apply equally to events or individuals. Application to events often gives rise to the so-called "thematic" use of RAs, otherwise it yields the "classificatory" use, though we assume a unified account of both uses (see Arsenijević et al. 2014 for discussion and further references). This is our starting point for modifiers that can be interpreted in an external fashion.

Ernst (1981) assumes that external modification can be paraphrased adverbially, as already noted above. For example, (51a) can be paraphrased as (54).

(54) Economically, Carter doesn't have a leg to stand on.

Outside the domain of idioms there are several other sorts of cases in which noun-modifying adjectives allow for an adverbial paraphrase (see, e.g., Morzycki 2015, Section 2.5, for a general overview). Here, we take inspiration from the literature on frequency adjectives (FAs, e.g., occasional, frequent, yearly; see Gehrke and McNally 2014, 2015 and references therein). Distinguishing between FAs that distribute exclusively over events (in the temporal domain, therefore "temporal FAs"; e.g., frequent, daily), and those that also allow for distribution in some other domain ("non-temporal FAs," e.g., The occasional sailor is 6 feet tall), Gehrke and McNally conjecture that there are different paths to an adverbial paraphrase with frequency adjectives. Temporal FAs can usually only be paraphrased adverbially when they modify an event nominal, as illustrated in (55).
a. They underwent a frequent check-up.
$\approx$ Frequently, they underwent a check-up.
b. $\quad \mathrm{A} /$ The frequent sailor strolled by.
* Frequently, a sailor strolled by.

However, there are exceptions to this generalization, addressed in detail in Gehrke and McNally (2014), in which, under particular conditions, an adverbial paraphrase is also possible with non-event nominals (56).

(56) a. She wrote me frequent letters. $\approx$ Frequently, she wrote me a letter.

b. She baked frequent cakes. $\approx$ Frequently, she baked a cake.

c. She drank frequent cups of coffee. $\approx$ Frequently, she drank a cup of coffee.

One of these conditions is that the events in question be atomic and individuated by one object participant per event (see op. cit. for a full discussion of the other conditions that have to be met). For example, while (56b) can be paraphrased adverbially, a sentence like She baked frequent cookies cannot, since cookie-baking events normally do not involve one cookie per event. This requirement of atomic units is reminiscent of our discussion of determiner variability with every in contrast to all in (49) and (50). 
To account for the exceptions to the generalization that temporal FAs require event nominals in order to be paraphrasable as sentential adverbs, Gehrke and McNally propose that while temporal FAs are always event modifiers (as indicated by their translation in (57a)), nominals can contribute an additional, contextually determined relation $R$ to an event, which we notate as $R_{\theta}$, as this relation usually gets resolved by the nominal argument's thematic relation to that event ((57b), where the asterisk on cake indicates predication over a plurality). Modification of the nominal by the FA in such a case results in (57c).
a. frequent: $\lambda e[$ frequent $(e)]$
b. cakes: $\lambda z \lambda e\left[\right.$ cake* $\left.(z) \wedge R_{\theta}(z, e)\right]$
c. frequent cakes: $\lambda z \lambda e\left[\right.$ cake* $(z) \wedge$ frequent $\left.(e) \wedge R_{\theta}(z, e)\right]$

Gehrke and McNally show that if the modified nominal is interpreted using a mechanism like pseudo-incorporation, the event variable in $(57 \mathrm{c})$ can be identified with the one described by the verb, as in (58) (here with a slight modification of the original formalization, which severed the external argument; again, see op. cit. for further details and discussion).
a. bake: $\lambda y \lambda x \lambda e$. bake $(x, y, e)$
b. bake frequent cakes: $\lambda y \lambda x \lambda e\left[\operatorname{bake}(x, y, e) \wedge\right.$ cake* $\left.^{*}(y) \wedge \operatorname{frequent}(e) \wedge R_{\theta}(y, e)\right]$

Thus, what is technically (internal) modification of the nominal ends up having an effect paraphrasable as external modification.

With these insights from FAs and RAs in mind, let us return to external modification in idioms, exemplified in (59).

(59) He kicked the political bucket.

$\approx$ He kicked the bucket in the political domain.

Recall our analysis of this idiom without the modifier in (37), repeated in (60).
a. $[\mathrm{vt} k i c k]:<\{\},\left\{\mathbf{R}\left(u_{e}, d(k i c k)\right)\right\},\left\{u_{e}\right\}>$
b. $[\mathrm{DP} z$ the bucket $]:<\{\},\left\{\mathbf{R}\left(u_{z}, d(\right.\right.$ bucket $\left.\left.)\right),\left|u_{z}\right|=1\right\},\left\{u_{z}\right\}>$
c. [vp kick the bucket]: $<\{\},\left\{\mathbf{R}\left(u_{e}, d([\mathrm{vp}\right.\right.$ kick the bucket $\left.])\right)$, $\mathbf{R}\left(u_{z}, d(\right.$ bucket $\left.)\right),\left|u_{z}\right|=1$, Theme $\left.\left(u_{z}, u_{e}\right)\right\},\left\{u_{e}, u_{z}\right\}>$

The analysis of the relational adjective political in (53) can be adapted as in (61a) (where the subscript indicates sortal non-specificity); its integration into the DP, in (61b), generalizes and adapts the treatment of FAs in (57). The rest of the analysis builds on (58).
a. political: $<\{\},\left\{R\left(u_{e} / x, d(\right.\right.$ politics $\left.)\right\},\left\{u_{e} x\right\}>$
b. [NPz political bucket]: $<\{\},\left\{\mathbf{R}\left(u_{z}, d(\right.\right.$ bucket $\left.)\right), R_{\theta}\left(u_{z}, u_{e}\right), R\left(u_{e}, d(\right.$ politics $\left.\left.)\right)\right\},\left\{u_{z}, u_{e}\right\}>$
c. [DPz the political bucket]: $<\{\},\left\{\mathbf{R}\left(u_{z}, d(\right.\right.$ bucket $\left.)\right),\left|u_{z}\right|=1, R_{\theta}\left(u_{z}, u_{e}\right), R\left(u_{e}, d(\right.$ politics $\left.\left.)\right)\right\}$, $\left\{u_{z}, u_{e}\right\}>$
d. [vP kick the political bucket] $:<\{\},\left\{\mathbf{R}\left(u_{e}, d([\mathrm{vP}\right.\right.$ kick the political bucket $\left.])\right)$,
$\mathbf{R}\left(u_{z}, d(\right.$ bucket $\left.)\right),\left|u_{z}\right|=1, R_{\theta}\left(u_{z}, u_{e}\right)$, Theme $\left(u_{z}, u_{e}\right), R\left(u_{e}, d(\right.$ politics $\left.\left.)\right), u_{e}=u_{e}\right\}$, $\left\{u_{e}, u_{z}, u_{e}\right\}>$


Since this analysis of external modification introduces the modifier within the DP, the same analysis should in principle extend to internal modification, on which the modifier and the noun describe the entity referred to by the DP under the same idiomatic guise; however, we acknowledge that conjunction modification remains a challenge. We also expect that determiner variability and modification should often, if not always, go hand in hand, as what legitimates both is the identification of the DP with some kind of participant in the event described by the idiom, even if by some sort of rational reconstruction.

\section{Conclusion}

In this paper we addressed the syntax/semantics interface problems posed by modification and determiner variability in idioms. We reviewed the major families of syntactic accounts addressing these issues, which all in one way or another place $\mathrm{V}$ and $\mathrm{N}$ in direct contact, independently of D (and potentially of modification), all of which have lacked an explicit semantics. We spelled out a semantic account that, in the spirit of these proposals, separates descriptive content composition from the composition of reference-related components of meaning, taking advantage of the separation to make use of distributional semantics for composing descriptive contents in a way that permits idiomatic interpretations and also opens the door to an account of what kind of determiner variability might be expected and under what conditions.

This discussion raises various larger questions for future research. We mention just two here. First, something like the dissociation of the interpretation of descriptive content from the interpretation of more properly reference-related expressions is found in other areas of the formal semantics literature. Perhaps most notably, the notion of reconstruction of descriptive content - effectively separating the locus of interpretation of an expression from its surface position - has been adopted in analyses of wh-moved and quantified expressions (see, e.g., Fox 2002; Sauerland 2004; Romoli 2015). An alternative approach to separating the two kinds of meaning has also been advocated by Lasersohn (2018), who argues that the semantic contribution of a noun is not a predicate, as widely assumed, but rather a variable whose possible values are effectively presupposed to be constrained by the nominal descriptive content.

In light of Lasersohn's proposal, it is interesting to consider the following comment by Sportiche (2005):

One might object to the very idea that there should be any syntactic reflex of V-N semantic selection because the selection could be recovered in some alternative way. One such way involve[s] presupposition (Fox, p.c., Spector, p.c.). Roughly, the idea would be as follows: there are independently attested observations about presupposition projection, which will account for the V-N selection facts if observed selectional patterns arise as a result of presupposition projection. For example, "Every $\mathrm{N}$ is intelligent" presupposes that such Ns are animate. And more generally "Det NP VP" presupposes that every NP satisfies the presuppositions of VP. (Sportiche 2005: 83)

It is, of course, well known that the basic sortal restrictions imposed by a verb on its complements are not at issue, unlike the matter of which specific individual(s) participate in the situation described by the verb. Perhaps less obvious is the fact that when we use a 
polysemous verb, the choice between the relevant sense of the verb and irrelevant senses is also typically not at issue. For instance, if I deny that I cut my finger, I am typically not denying that my finger is something that can take an incision. Similarly, I am not denying that what cutting would involve with a finger is making an incision in it, as opposed to some other action that could be described by the verb, such as reducing or stopping. It may be, then, that the details of the composition of the complex descriptive contents we propose to compose via distributional semantic methods belong in a separate semantic dimension (in the sense of Potts 2005) from the ascription of those contents to discourse referents. In this case, the appropriately disambiguated components of the idiom could be inserted in the at-issue dimension of the semantics where they belong, and composition could proceed as is generally assumed. Such an approach would share important similarities with the system developed in Asher (2011) and in Asher and colleagues' ongoing work. Clearly, a comparison of these different strategies for distinguishing types of content is in order.

Second, our analysis foregrounds the difficult question of what constitutes an idiom and the implications of that question for how semantic composition is understood. Consider, for example, the pair in (61). (61a) is commonly treated as an idiom, whereas it is less obvious how to categorize (61b) - as an idiom, or as figurative language, if such a thing can be properly distinguished.

$$
\begin{aligned}
& \text { a. to touch a nerve } \\
& \text { b. to touch (on) a subject }
\end{aligned}
$$

The system we advocate analyses both of these, as well as "literal" uses of touch, via the same sort of effectively "co-compositional" operation (Pustejovsky 1995). The fact that we are arguably less conscious of the co-compositional nature of meaning construction when the situations described are concrete is a phenomenon that merits further exploration, as do the implications of the particular approach to co-compositionality that we adopt here, which has clear advantages for the analysis of idioms but challenges widely-held views that limit linguistically-relevant lexical meaning to exactly that which is entailed. Interestingly, however, using the same co-compositional operation to handle all sorts of V-N combinations renders idioms just one extreme of a continuum from non-transparent V-N combinations to combinations like ride a bike, related to incorporated forms such as bike ride, which often show some degree of non-transparency, to combinations that are commonly not analyzed as idioms. In other words, idioms turn out to be no different from any other combinations of words, simply more spectacular. - sdf

\section{Acknowledgments}

We thank the organizers of BCGL 8 for getting us started on this topic, and two anonymous reviewers, Chris Barker, Manfred Sailer, Henriette de Swart, and audiences at the 16th Szklarska Poreba Workshop, the OASIS Workshop on Nominal Phrase Meaning (Humboldt Universität zu Berlin), Utrecht University, and the University of Konstanz for feedback. This project has received funding from the European Research Council (ERC) under the European Union's Horizon 2020 research and innovation program (grant agreement No 715154), grant FFI2016-76045-P (AEI/MINEICO/FEDER, UE), a Salvador de Madariaga mobility grant from the Spanish Ministry of Education, Culture and Sports, an ICREA Academia award, and the Alexander von Humboldt Foundation.

\section{References}


Abney, Steven P. 1987. The English noun phrase in its sentential aspect. Cambridge, MA: MIT dissertation.

Aguilar Guevara, Ana. 2014. Weak definites: Semantics, lexicon and pragmatics. LOT Dissertation Series $360 . \quad$ Utrecht: https://www.lotpublications.nl/Documents/360_fulltext.pdf (accessed 19 November 2018).

Aguilar Guevara, Ana \& Joost Zwarts. 2011. Weak definites and reference to kinds. In Nan Li \& David Lutz (eds.), Proceedings of Semantics and Linguistic Theory (SALT) 20, 176196. Ithaca, NY: Linguistic Society of America and Cornell Linguistic Circle. http://dx.doi.org/10.3765/salt.v20i0.2583 (accessed 19 November 2018).

Arsenijević, Boban, Gemma Boleda, Berit Gehrke \& Louise McNally. 2014. Ethnic adjectives are proper adjectives. In Rebekah Baglini, Timothy Grinsell, Jonathan Keane, Adam Roth Singerman \& Julia Thomas (eds.), CLS 46-1 The main session: Proceedings of the 46th Annual Meeting of the Chicago Linguistic Society, 17-30. Chicago: Chicago Linguistic Society.

Asher, Nicholas. 2011. Lexical meaning in context. Cambridge: Cambridge University Press.

Bargmann, Sascha, Berit Gehrke \& Frank Richter. 2018. Modification of literal meaning in semantically non-decomposable idioms. Ms. University of Frankfurt and Humboldt University of Berlin.

Bargmann, Sascha \& Manfred Sailer. 2018. The syntactic flexibility of semantically nondecomposable VP-idioms. In Manfred Sailer \& Stella Markantonatou (eds.), Multiword expressions: Insights from a multi-lingual perspective, 1-29. Berlin: Language Science Press.

Baroni, Marco \& Roberto Zamparelli. 2010. Nouns are vectors, adjectives are matrices: Representing adjective-noun constructions in semantic space. In Hang Li \& Lluís Márquez (eds.) Proceedings of the 2010 Conference on Empirical Methods in Natural Language Processing, 1183-1193. Cambridge, MA: Association for Computational Linguistics. http://www.aclweb.org/anthology/D10-1115 (accessed 19 November 2018).

Baroni, Marco, Georgiana Dinu \& Germán Kruszewski. 2014. Don’t count, predict! A systematic comparison of context-counting vs. context-predicting semantic vectors. In Kristina Toutanova \& Hua Wu (eds.), Proceedings of the 52nd Annual Meeting of the Association for Computational Linguistics (Volume 1: Long Papers), 238-247. Baltimore, MD: Association for Computational Linguistics. http://www.aclweb.org/anthology/P141023 (accessed 19 November 2018).

Boleda, Gemma \& Aurélie Herbelot (eds.). 2016. Formal distributional semantics. Special issue of Computational Linguistics 42(4). http://cognet.mit.edu/journals/computationallinguistics/42/4 (accessed 19 November 2018).

Borik, Olga \& Berit Gehrke. 2015. An introduction to the syntax and semantics of pseudoincorporation. In Olga Borik \& Berit Gehrke (eds.), The syntax and semantics of pseudoincorporation, 1-43. Leiden: Brill.

Bowdle, Brian F. \& Dedre Gentner. 2005. The career of metaphor. Psychological Review 112(1). 193-206. http://dx.doi.org/10.1037/0033-295X.112.1.193 accessed 19 November 2018).

Bruening, Benjamin. 2015. Idioms: Movement and non-movement dependencies. Ms., University of Delaware. http://udel.edu/ bruening/Downloads/IdiomsMovement1.pdf (accessed 19 November 2018).

Bruening, Benjamin, Xuyen Dinh \& Lan Kim. 2018. Selection, idioms, and the structure of nominal phrases with and without classifiers. Glossa: a journal of general linguistics 3(1). 42. https://doi.org/10.5334/gjgl.288 (accessed 19 November 2018). 
Carlson, Gregory N. 1977. Reference to kinds in English. Amherst, MA: University of Massachusetts at Amherst dissertation. Published 1980 by Garland Press, New York.

Carlson, Gregory N. 2003. Weak indefinites. In Martine Coene \& Yves D'hulst (eds.), From NP to DP, 195-210. Amsterdam: John Benjamins.

Cecchetto, Carlo \& Caterina Donati. 2015. (Re)labeling. Cambridge, MA: MIT Press.

Chae, Hee-Rahk. 2015. Idioms: Formally flexible but semantically non-transparent. In Hai Zhao (ed.), 29th Pacific Asia Conference on Language, Information and Computation: Posters, 46-54. Shanghai. http://aclweb.org/anthology/Y15-2006 (accessed 19 November 2018).

Collins, Chris. 2007. Home sweet home. NYU Working Papers in Linguistics 1. 1-34.

Cooper, Robin. 2005. Records and record types in semantic theory. Journal of Logic and Computation 15(2). 99-112. https://doi.org/10.1093/logcom/exi004 (accessed 19 November 2018).

Cserép, Attila. 2010. Premodification in idioms. Argumentum 6. 100-112. http://epa.oszk.hu/00700/00791/00007/pdf/cserepa.pdf (accessed 19 November 2018).

Diesing, Molly. 1992. Indefinites. Cambridge, MA: MIT Press.

Ernst, Thomas. 1981. Grist for the linguistic mill: Idioms and 'extra' adjectives. Journal of Linguistic Research 1(3). 51-68.

Espinal, M. Teresa \& Jaume Mateu. 2010. On classes of idioms and their interpretation. Journal of Pragmatics 42(5). 1397-1411. https://doi.org/10.1016/j.pragma.2009.09.016 (accessed 19 November 2018).

Everaert, Martin. 2017. Idioms: What you see is what you get? Paper presented at The Syntax of Idioms Workshop, Utrecht University, 20 January.

Farkas, Donka \& Henriëtte de Swart. 2003. The semantics of incorporation: From argument structure to discourse transparency. Stanford, CA: CSLI Publications.

Fellbaum, Christiane. 2015. Is there a grammar of idioms? Paper presented at the 8th Brussels Conference on Generative Linguistics, Brussels, 4-5 June.

Fox, Danny. 2002. Antecedent-contained deletion and the copy theory of movement. Linguistic Inquiry 33(1). 63-96. https://doi.org/10.1162/002438902317382189 (accessed 19 November 2018).

Garrette, Dan, Katrin Erk \& Raymond Mooney. 2011. Integrating logical representations with probabilistic information using Markov logic. Proceedings of the Ninth International Conference on Computational Semantics (IWCS 2011). http://aclweb.org/anthology/W110112 (accessed 19 November 2018).

Gehrke, Berit. To appear. Event kinds. In R. Truswell (ed.), The Oxford handbook of event structure, Oxford: Oxford University Press.

Gehrke, Berit \& Louise McNally. 2014. Event individuation by objects: Evidence from frequency adjectives. In Urtzi Etxeberria, Annamaria Fălăuş, Aritz Irurtzun \& Bryan Leferman (eds.), Proceedings of Sinn und Bedeutung 18, 146-163. Bayonne and VitoriaGasteiz. $\quad$ https://semanticsarchive.net/sub2013/SeparateArticles/Gehrke-McNally.pdf (accessed 19 November 2018).

Gehrke, Berit \& Louise McNally. 2015. Distributional modification: The case of frequency adjectives. Language 91(4). 837-870. https://doi.org/10.1353/lan.2015.0065 (accessed 19 November 2018).

Glasbey, Sheila R. 2003. Let's paint the town red for a few hours: Composition of aspect in idioms. In A.M. Wellington (ed.), Proceedings of the ACL Workshop: The Lexicon and Figurative Language, 42-48. http://aclweb.org/anthology/W03-1406 (accessed 19 November 2018). 
Glasbey, Sheila R. 2007. Aspectual composition in idioms. In Louis de Saussure, Jacques Moeschler \& Genoveva Puskas (eds.), Recent advances in the syntax and semantics of tense, aspect and modality, 71-87. Berlin: Mouton de Gruyter.

Glucksberg, Sam. 2001. Understanding figurative language: From metaphor to idioms. Oxford: Oxford University Press.

Grimm, Scott \& Louise McNally. 2015. The -ing dynasty: Rebuilding the semantics of nominalizations. In Sarah D'Antonio, Mary Moroney \& Carol Rose Little (eds.), Proceedings of the 25th Semantics and Linguistic Theory Conference (SALT), 82-102. Ithaca, NY: Linguistic Society of America and Cornell Linguistics Circle. http://dx.doi.org/10.3765/salt.v25i0.3070 (accessed 19 November 2018).

Hedges, Jules \& Mehrnoosh Sadrzadeh. 2016. A generalised quantifier theory of natural language in categorical compositional distributional semantics with bialgebras. CoRR abs/1602.01635. http://arxiv.org/abs/1602.01635 (accessed 19 November 2018).

Hogeweg, Lotte. To appear. Suppression in interpreting adjective noun combinations and the nature of the lexicon. Journal of Semantics.

Jackendoff, Ray. 1993. Home is subject to Principle A. Linguistic Inquiry 24(1). 173-177.

Jackendoff, Ray. 1997. The architecture of the language faculty. Cambridge, MA: MIT Press.

Kamp, Hans \& Uwe Reyle. 1993. From discourse to logic: Introduction to modeltheoretic semantics of natural language, formal logic and discourse representation theory. Dordrecht: Kluwer.

Klein, Dan \& Christopher Manning. 2002. Fast exact inference with a factored model for natural language parsing. In Suzanna Becker, Sebastian Thrun \& Klaus Obermayer (eds.), Advances in Neural Information Processing Systems 15 (NIPS 2002), 3-10. Cambridge, MA: MIT Press. http://papers.nips.cc/paper/2325-fast-exact-inference-with-a-factoredmodel-for-natural-language-parsing.pdf (accessed 19 November 2018).

Koenig, Jean-Pierre \& Gail Mauner. 1999. A-definites and the discourse status of implicit arguments. Journal of Semantics 16(3). 207-236. https://doi.org/10.1093/jos/16.3.207 (accessed 19 November 2018).

Landauer, Thomas K. \& Susan T. Dumais. 1997. A solution to Plato's problem: The latent semantic analysis theory of acquisition, induction, and representation of knowledge. Psychological Review, 104(2). 211-240. http://dx.doi.org/10.1037/0033-295X.104.2.211 (accessed 19 November 2018).

Lasersohn, Peter. 2018. Common nouns as variables: Evidence from conservativity and the temperature paradox. In Robert Truswell, Chris Cummins, Caroline Heycock, Brian Rabern \& Hannah Rohde (eds.), Proceedings of Sinn und Bedeutung 21, 731-746. https://semanticsarchive.net/Archive/DRjNjViN/SuB21.pdf (accessed 19 November 2018).

Lebani, Gianluca E., Marco S.G. Senaldi \& Alessandro Lenci. 2016. Modeling idiom variability with entropy and distributional semantics. In Johannes Wahle, Marisa Köllner, Harald Baayen, Gerhard Jäger \& Tineke Baayen-Oudshoorn (eds.), Proceedings of the 6th Conference on Quantitative Investigations in Theoretical Linguistics. http://dx.doi.org/10.15496/publikation-8615 (accessed 19 November 2018).

Lenci, Alessandro. 2018. Distributional Models of Word Meaning. Annual Review of Linguistics 4(1). 151-171.

Lewis, M. \& M. Steedman. 2013. Combined distributional and logical semantics. Transactions of the Association for Computational Linguistics 1. 179-192. https://transacl.org/ojs/index.php/tacl/article/view/93/11 (accessed 19 November 2018).

Liberman, Anatoly. 2016. More on idioms: "kick the bucket". Blog post dated 17 February 2016. https://blog.oup.com/2016/02/kick-the-bucket-idiom-origin-etymology/ (accessed 19 November 2018). 
Liu, Pengfi, Kaiyu Qian, Xipeng Qiu \& Xuanjing Huang. 2017. Idiom-aware compositional distributed semantics. In Martha Palmer, Rebecca Hwa \& Sebastian Riedel (eds.), Proceedings of the 2017 Conference on Empirical Methods in Natural Language Processing, 1204-1213. Copenhagen: Association for Computational Linguistics. http://aclweb.org/anthology/D17-1124 (accessed 19 November 2018).

Massam, Diane. 2001. Pseudo noun incorporation in Niuean. Natural Language and Linguistic Theory 19(1). 153-197. https://doi.org/10.1023/A:1006465130442 (accessed 19 November 2018).

McClure, Scott. 2011. Modification in non-combining idioms. Semantics and Pragmatics 4. 1-7. http://dx.doi.org/10.3765/sp.4.7 (accessed 19 November 2018).

McNally, Louise. 1992. An interpretation for the English existential construction. University of California, Santa Cruz, dissertation.

McNally, Louise. 2017. Kinds, descriptions of kinds, concepts, and distributions. In Kata Balogh \& Wiebke Petersen (eds.), Bridging formal and conceptual semantics. Selected papers of BRIDGE-14, 39-61. Düsseldorf: dup. http://dup.oa.hhu.de/570/ (accessed 19 November 2018).

McNally, Louise \& Gemma Boleda. 2004. Relational adjectives as properties of kinds. In Olivier Bonami \& Patricia Cabredo Hofherr (eds.), Empirical Issues in Formal Syntax and Semantics 5. 179-196. http://www.cssp.cnrs.fr/eiss5/mcnally-boleda/mcnally-boledaeiss5.pdf (accessed 19 November 2018).

McNally, Louise \& Gemma Boleda. 2017. Conceptual vs. referential affordance in concept composition. In Yoad Winter \& James A. Hampton (eds.), Compositionality and concepts in linguistics and psychology, 245-267. Berlin: Springer. https://doi.org/10.1007/978-3319-45977-6 10 (accessed 19 November 2018).

Mikolov, Tomas, Kai Chen, Greg Corrado \& Jeffrey Dean. 2013. Efficient estimation of word representations in vector space. Paper presented at the International Conference on Learning Representations (ICLR), Scottsdale, AZ, 2-4 May.

Morzycki, Marcin. 2015. Modification. Cambridge: Cambridge University Press.

Nicolas, Tim. 1995. Semantics of idiom modification. In Martin Everaert, Erik-Jan van der Linden, André Schenk \& Rob Schreuder (eds.), Idioms: Structural and psychological perspectives, 233-252. Hillsdale, NJ: Lawrence Erlbaum Associates.

Nunberg, Geoffrey, Ivan A. Sag \& Thomas Wasow. 1994. Idioms. Language 70(3). 491-538. https://doi.org/10.1353/lan.1994.0007 (accessed 19 November 2018).

Paperno, Denis, Nghia The Pham \& Marco Baroni. 2014. A practical and linguisticallymotivated approach to compositional distributional semantics. In Kristina Toutanova \& Hua Wu (eds.), Proceedings of the 52nd Annual Meeting of the Association for Computational Linguistics (Volume 1: Long Papers), 90-99. Baltimore, MD: Association for Computational Linguistics. http://www.aclweb.org/anthology/P/P14/P14-1009 (accessed 19 November 2018).

Pham, Nghia The. 2016. Sentential representations in distributional semantics. Trento: University of Trento dissertation.

Pollard, Carl \& Ivan A. Sag. 1994. Head-Driven Phrase Structure Grammar. Stanford, CA: CSLI Publications.

Potts, Christopher. 2005. The logic of conventional implicatures. Oxford: Oxford University Press.

Pustejovsky, James. 1995. The generative lexicon. Cambridge, MA: MIT Press.

Romoli, Jacopo. 2015. A structural account of conservativity. Semantics-Syntax Interface 2(1). 28-57.

Rubio Fernández, Paula. 2006. Delimiting the power of suppression in lexical processing: the question of below-baseline performance. UCL Working Papers in Linguistics 18. 119-137. 
Sailer, Manfred. 2004. Local Semantics in Head-Driven Phrase Structure Grammar. In Olivier Bonami and Patricia Cabredo Hofherr (eds.), Empirical Issues in Syntax and Semantics 5, 197-214. http://www.cssp.cnrs.fr/eiss5/sailer/sailer-eiss5.pdf (accessed 19 November 2018).

Sailer, Manfred. 2017. The multi-dimensional semantics of kinegrams. Paper presented at the 4th European Workshop on HPSG, Paris, 24-25 March.

Sauerland, Uli. 2004. The interpretation of traces. Natural Language Semantics 12(1). 63127. https://doi.org/10.1023/B:NALS.0000011201.91994.4f (accessed 19 November 2018).

Schwarz, Florian. 2014. How weak and how definite are Weak Definites? In Ana Aguilar Guevara, Bert Le Bruyn \& Joost Zwarts (eds.), Weak referentiality, 213-236. Amsterdam: John Benjamins.

Senaldi, Marco S.G., Gianluca E. Lebani and Alessandro Lenci. 2016. Lexical variability and compositionality: Investigating idiomaticity with Distributional Semantic Models. In Valia Kordoni, Kostadin Cholakov, Markus Egg, Stella Markantonatou \& Preslav Nakov (eds.), Proceedings of the 12th Workshop on Multiword Expressions, 21-31. Berlin: Association for Computational Linguistics. http://aclweb.org/anthology/W16-1803 (accessed 19 November 2018).

Sportiche, Dominique. 2005. Division of labor between Merge and Move: Strict locality of selection and apparent reconstruction paradoxes. Ms. UCLA. https://ling.auf.net/lingbuzz/000163 (accessed 19 November 2018).

Stathi, Ekatherini. 2007. A corpus-based analysis of adjectival modification in German idioms. In Christiane Fellbaum (ed.), Idioms and collocations: Corpus-based linguistic and lexicographic studies, 81-108. London/New York: Continuum.

Svenonius, Peter. 2005. Extending the Extension Condition to discontinuous idioms. Linguistic Variation Yearbook 5. 227-263. https://doi.org/10.1075/livy.5.08sve (accessed 19 November 2018).

Swinney, David. 1979. Lexical access during sentence comprehension: (Re)consideration of context effects. Journal of Verbal Learning and Verbal Behavior 18(6). 645-660. https://doi.org/10.1016/S0022-5371(79)90355-4. (accessed 19 November 2018).

Terzi, Arhonto. 2010. On null spatial Ps and their arguments. Catalan Journal of Linguistics 9. 167-187. https://revistes.uab.cat/catJL/article/view/v9-terzi/108 (accessed 19 November 2018).

Titone, Debra A. \& Cynthia M. Conine. 1999. On the compositional and noncompositional nature of idiomatic expressions. Journal of Pragmatics 31(12). 1655-1674. https://doi.org/10.1016/S0378-2166(99)00008-9 (accessed 19 November 2018).

Van Geenhoven, Veerle. 1996. Semantic incorporation and indefinite descriptions: Semantic and syntactic aspects of West Greenlandic noun incorporation. Tübingen: Universität Tübingen dissertation.

Weinreich, Uriel. 1969. Problems in the analysis of idioms. In Jaan Puhvel (ed.) Substance and structure of language, 23-81. Berkeley, CA: University of California Press.

\section{Appendix}

Alphabetical list of the idiomatic expressions mentioned in this article, with glosses from Merriam Webster's Online Dictionary (https://www.merriam-webster.com) unless otherwise noted.

- to bark up the wrong tree: to promote or follow a mistaken course (as in doing research) 
- to beat a dead horse: to keep talking about a subject that has already been discussed or decided; to waste time and effort trying to do something that is impossible

- to bend X's ear: to talk to someone for a long time

- between the devil and the blue sea: faced with two equally objectionable alternatives

- to bite one's tongue: to hold back (as from a reluctance to offend) a remark one would like to make

- to blow off steam: to release pent-up emotions

- to break new ground: to make or show discoveries

- to bury the hatchet: to settle a disagreement, become reconciled

- to cast/throw pearls before swine: to give or offer something valuable to someone who does not understand its value

- castle in the air: an impracticable project

- to chew the fat: to make friendly familiar conversation

- to close up shop: to go out of business forever or stop performing all services or activities for a period of time

- to cut corners: to perform some action in the quickest, easiest, or cheapest way

- to eat humble pie: to admit that one was wrong or accept that one has been defeated

- to have a ball: to have fun, to spend time in a very enjoyable way

- not have a leg to stand on: to have no support for what one thinks, says, or does

- to hit home: to become very clear and obvious in usually a forceful or unpleasant manner

- to hit/strike/touch a nerve: to make someone feel angry, upset, embarrassed, etc.

- to jump on the bandwagon: to join or give support to a party or movement that seems to be assured of success (Collins English Dictionary, https://www.collinsdictionary.com/dictionary/english)

- to kick the bucket: to die

- to lend a hand: to provide help

- head or tail: beginning or end; one thing or another; something definite

- to make tracks: to proceed at a walk or run; to go in a hurry

- out of the picture: not involved or playing a part in something: not in the same situation or relationship

- to pull X's leg: to make someone believe something that is not true as a joke; to trick or lie to someone in a playful way

- to pull strings: to exert hidden influence or control

- to rock the boat: to do something that disturbs the equilibrium of a situation

- to seek revenge: to plan to hurt the person who is responsible for an injury to oneself, a loved one, etc.

- to shoot the breeze: to converse idly

- to smell a rat: to have a suspicion of something wrong

- under one's wing: under one's protection, in one's care

- the world is someone's oyster: used to say that someone's life is good and he or she has the ability to do whatever he or she wants to do 